\title{
Antifungal Activity of Saponins from the Fruit Pericarp of Sapindus mukorossi against Venturia inaequalis and Botrytis cinerea
}

Franziska M. Porsche, ${ }^{\dagger}$ Julius Kühn-Institute, Federal Research Center for Cultivated Plants, Institute for Plant Protection in Fruit Crops and Viticulture, 69221 Dossenheim, Germany; Daniel Molitor, Marco Beyer, Sophie Charton, and Christelle André, Luxembourg Institute of Science and Technology, Environmental Research and Innovation Department, 4422 Belvaux, Luxembourg; and Andreas Kollar, Julius Kühn-Institute, Federal Research Center for Cultivated Plants, Institute for Plant Protection in Fruit Crops and Viticulture

\begin{abstract}
The antifungal activity of an aqueous extract (AE) and the solid fraction of a chloroform-methanol fruit pericarp extract (CME) of Sapindus mukorossi resolved in water was tested for the first time against Venturia inaequalis and Botrytis cinerea - two important fungal pathogens worldwide. In the greenhouse, a CME ( $1 \% \mathrm{vol} / \mathrm{vol})$ spray significantly reduced $V$. inaequalis symptoms and sporulation (99\%) on apple seedling leaves $(P \leq 0.05)$. In field trials, applications of $\mathrm{AE}(1 \% \mathrm{vol} / \mathrm{vol})$ reduced the disease severity of $B$. cinerea on grape, on average, by $63 \%$. Extracts

were fractionated by high-performance liquid chromatography and the bioefficacy of the fractions was tested in vitro. Some components of the most fungicidal fraction were identified by liquid chromatographyhigh resolution mass spectrometry as saponins: sapindoside B (accounting for $\geq 98 \%$ of the total constituents), hederagenin-pentosylhexoside, and oleanolic acid-hexosyl-deoxyhexosyl-hexoside. This fraction inhibited the mycelial growth of $V$. inaequalis and B. cinerea by 45 and $43 \%$, respectively.
\end{abstract}

The frequent use of synthetic chemical pesticides is associated with risks for human health and the environment (Gilliom 2007; Parween et al. 2016; Sanborn et al. 2007, 2012; United States National Research Council Board of Agriculture 1987, 1993). In addition, many plant pathogens have developed resistance against synthetic chemical fungicides (Chapman et al. 2011; Köller and Wilcox 2001; Köller et al. 2005). Consequently, pesticide use is increasingly questioned and regulated (Agnello 2017; USDA-NASS 2006). In perennial crops such as apple or grapevine pesticide application frequency is considerably higher compared with most annual crops (JKI 2017; Penell 2006; Pertot 2013; Roßberg 2016) partly because the growers of perennial crop cannot take advantage of the pathogen-suppressing effect of annual crop rotation.

Venturia inaequalis (Cooke) G. Winter and Botrytis cinerea Pers. (teleomorph: Botryotinia fuckeliana (de Bary) Whetzel) are important fungal plant pathogens causing severe losses in terms of fruit quality and quantity. Apple scab, caused by $V$. inaequalis, is the most detrimental disease of apple trees worldwide (MacHardy 1996). The failure to control apple scab results in an extensive reduction in yield and a decrease in the market value of fruit (Carisse and Dewdney 2002). Grape bunch rot, also referred to as gray mold, is caused by Botrytis cinerea. It causes severe economic damage worldwide on grapevine (Vitis vinifera L.) (Kassemeyer and Berkelmann-Löhnertz 2009), as well as on more than 200 other, mainly dicotyledonous plant species (Williamson et al. 2007). When infecting grape, $B$. cinerea reduces yield as well as wine quality (in terms of off-flavors, oxidative damages, unstable color, premature aging, and difficulties in clarification) (Ribereau-Gayon 1983).

To control fungal diseases effectively and to reduce the risk of environmental impacts by synthetic chemical fungicides, secondary plant metabolites and their derivatives have been evaluated as antifungal agents for disease management (Choi et al. 2006; Thuerig et al. 2016; Wilson et al. 1997). The problem of the development

${ }^{\dagger}$ Corresponding author: F. M. Porsche,

E-mail: franziska.porsche@julius-kuehn.de

Funding: The Institut Viti-Vinicole (Remich/Luxembourg) provided financial support in the framework of the research project "ProVino-Pesticide reduction in viticulture".

Accepted for publication 8 November 2017.

C) 2018 The American Phytopathological Society of fungicide resistance may also occur with substances derived from natural compounds such as the strobilurin fungicides (Carisse and Dewdney 2002; Chapman et al. 2011). However, such compounds tend to be more biodegradable and express lesser side effects on compartments of the biotic environment (Gabaston et al. 2017; Palou et al. 2016; Romanazzi et al. 2012).

Several studies have been published that focus on biological activity of saponins as potential alternative biological pesticides (Bengtsson et al. 2009; Chapagain et al. 2007; Molitor et al. 2010; Porsche 2015; Porsche and Kollar 2013). Saponins are surface-active glycosides synthesized continuously in roots, leaves, and fruit of higher plants, and have membrane-permeabilizing properties (Augustin et al. 2011). They consist of nonsugar aglycones linked to sugar chain units. According to the structure of the aglycone, saponins are classified as triterpenoid, steroidal, or steroidal alkaloids (Augustin et al. 2011). Saponins are regarded as preformed compounds against plant pathogen attack (Osbourn 1996) and display antifungal activity (Chapagain et al. 2007; Saha et al. 2010).

Sapindus mukorossi Gaertn., known as soap nut tree, is a plant of the family Sapindaceae which is widely distributed in tropical and subtropical regions of Asia. The plant has traditionally been used as a source of natural surfactants and contains high levels of water-soluble triterpenic saponins (Huang et al. 2008). Rafi et al. (2015) reported a strong inhibitory effect of the fruit extract of $S$. mukorossi against the root-infecting fungi Rhizoctonia solani, Fusarium spp., and Macrophomia phaseolina. However, studies of the saponins from S. mukorossi have been carried out against dermatophytes (Tamura et al. 2001; Wu et al. 2014) and bacteria (Ibrahim et al. 2006; Sharma et al. 2013) but information regarding its performance against plant-pathogenic fungi is scarce (Koch et al. 2013; Saha et al. 2010). Consequently, the objectives of this study were to (i) test the antifungal activity of fruit pericarp extracts from $S$. mukorossi against Venturia inaequalis under in vitro conditions and in the greenhouse, (ii) test the antifungal activity of fruit pericarp extracts from $S$. mukorossi against $B$. cinerea under in vitro and field conditions, and (iii) purify, characterize, and identify major compounds of fungicidal extract fractions using high-performance liquid chromatography (HPLC) and ultrahigh-performance liquid chromatography triple time-of-flight (UPLC-TripleTOF) analysis.

\section{Materials and Methods}

Reagents and chemicals. All organic solvents were of analytical grade and were purchased from Sigma-Aldrich (Steinheim, Germany). Unless specified otherwise, ultrapure water (Milli-Q; Millipore, Billerica, MA) was used for all solutions and dilutions. Chromatographic-grade 
acetonitrile (ACN) was used for UPLC and HPLC analysis (SigmaAldrich).

Fungal isolates and culturing conditions. A single-spore isolate of $V$. inaequalis (V1) was obtained from the culture collection of the Julius Kühn-Institute in Dossenheim. The fungal strain was isolated from infected tissue of the apple cultivar Golden Delicious (Kollar 1994). The B. cinerea isolate B05.10 was provided by Anne-Sophie Walker from the Institut National de la Recherche Agronomique (Thiverval-Grignon, France) and isolated from an unknown host in Germany (Amselem et al. 2011). The fungal isolates were maintained on potato dextrose agar (PDA; 0.4\% [wt/vol] potato extract, 2\% [wt/vol] dextrose, and $1.5 \%$ [wt/vol] agar) at $20^{\circ} \mathrm{C}$. For long-term storage, mycelial agar plugs of both isolates were stored at $-80^{\circ} \mathrm{C}$.

Extraction and isolation. Aqueous extract. Aqueous extract (AE) was prepared by dissolving $20 \mathrm{~g}$ of fruit pericarp powder of $S$. mukorrossi (Waschnusspulver; Fair Natur, München, Germany) in $100 \mathrm{ml}$ of ultrapure water. The suspension was incubated on a rotary shaker $(100 \mathrm{rpm})$ for $60 \mathrm{~min}$ at $20^{\circ} \mathrm{C}$. The fruit pericarp extract of $S$. mukorossi was centrifuged for $20 \mathrm{~min}$ at 15,300 $\times g$ (Beckman JA-14; Beckman Coulter, Brea, CA) at $20^{\circ} \mathrm{C}$ and the supernatant was transferred into new tubes and frozen $\left(-20^{\circ} \mathrm{C}\right)$ as a stock solution. Test samples were diluted in various concentrations as outlined below for further experiments.

Chloroform-methanol extract. Fruit pericarps of S. mukorrossi were purchased from the Handelsvertretung für Naturprodukte, Leisnig, Germany. Finely ground pericarps of $S$. mukorossi $(200 \mathrm{~g})$ were extracted with $950 \mathrm{ml}$ of a CHCl $3-\mathrm{MeOH}-\mathrm{H}_{2} \mathrm{O}$ (12:25:10) monophasic mixture for $30 \mathrm{~min}$ on a horizontal-shaker (100 rpm). $\mathrm{CHCl}_{3}$ (125 ml) and $\mathrm{H}_{2} \mathrm{O}(125 \mathrm{ml})$ were added to achieve phase separation. The extracts were agitated for $10 \mathrm{~min}$ and centrifuged for $15 \mathrm{~min}$ at $15,300 \times g\left(\right.$ Beckman JA-14; Beckman Coulter) at $20^{\circ} \mathrm{C}$. The methanol layer was collected and concentrated under reduced pressure. The remaining methanol in the aqueous layer was evaporated. The fraction was lyophilized, ground to a fine powder, and dissolved in water for further experiments.

Inhibitory effects of the fruit pericarp extract of $S$. mukorossi under in vitro conditions. Chloroform-methanol extract (CME) and AE from $S$. mukorossi were tested for their inhibitory effect on conidial germination of $V$. inaequalis and $B$. cinerea. Stock suspensions of conidia $\left(10^{5} / \mathrm{ml}\right)$ from $V$. inaequalis were prepared for each experiment by shaking four to five scab-infected apple leaves for $10 \mathrm{~min}$ in water $(50 \mathrm{ml})$. B. cinerea conidia were produced on pinto bean $\operatorname{agar}(5 \%$ [wt/vol] fine-ground pinto bean powder, $0.5 \%$ [wt/vol] glucose, and $1.5 \%$ [wt/vol] agar] at $25^{\circ} \mathrm{C}$ under near-UV light. Conidia were aseptically harvested after 14 days by suction with a malt-yeast medium ( $2 \%$ [wt/vol] malt extract, $0.2 \%$ [wt/vol] yeast extract, $1 \%$ [wt/vol] sucrose, $1 \%$ [wt/vol] fructose, and $1 \%$ [wt/vol] aspartic acid) and diluted to obtain a final concentration of $10^{5} / \mathrm{ml}$. Conidia $(0.5 \mathrm{ml})$ were mixed in cavities of 6 microwell plates (Greiner bio-one, Frickenhausen, Germany) with the test compound dissolved in $0.5 \mathrm{ml}$ of water. Final fruit pericarp extract concentrations were 1, 5, 10, 50, $100,1,000,5,000,10,000,20,000$, and 30,000 ppm for $V$. inaequalis and 100, 1,000, 10,000, 50,000, 75,000, 100,000, 125,000, 200,000, 250,000 and $300,000 \mathrm{ppm}$ for $B$. cinerea. The control consisted of a conidial suspension $(0.5 \mathrm{ml})$ dissolved in ultrapure water $(0.5 \mathrm{ml})$. After $24 \mathrm{~h}$, the percentage of germinated conidia (100 randomly selected) was assessed under a light microscope and treatments were compared with a water control, which was set to $100 \%$ germination for reasons of standardization. The percentage of germinated conidia in the control was $95 \%$ for $B$. cinerea and $87 \%$ for $V$. inaequalis. Conidia with germ tubes at least half as long as the conidia were considered to be germinated. The tests were repeated three times per test solution and data are presented as the average of three experiments. For each concentration $(X)$ of the fruit pericarp extract of $S$. mukorossi, the inhibition of conidial germination $(Y)$ was calculated as $100 \%$ minus the conidial germination in the respective treatment in relation to the conidial germination of the untreated control.

Data of CME and AE were log-transformed and concentrations inhibiting conidial germination at $50 \%\left(\mathrm{IC}_{50}\right)$ were estimated by plotting the $\mathrm{x}-\mathrm{y}$ values and fitting the data with a sigmoidal dose-response model (variable slope) in the GraphPad Prism 7 software (La Jolla, CA). The sigmoidal equation was

$Y=$ Bottom $+($ Top - Bottom $) /\left[1+10_{\mathrm{e}}^{(\operatorname{LogIC} 50-x)-\text { Hill Slope }}\right]$, where $Y$ is the percent inhibition of conidial germination compared with the control, $x$ the corresponding concentration of the $S$. mukorossi extract (\%), Bottom is the $Y$ value at the bottom plateau, and Top is the $Y$ value at the top plateau. The Hill Slope describes the slope of the curve. Log $\mathrm{IC}_{50}$ is the value when the response is halfway between Bottom and Top. In addition, coefficients of determination $\left(R^{2}\right)$ were calculated. Data were further analyzed using an unpaired two-sided $t$ test to determine significant differences $(P \leq 0.05)$ between $\mathrm{IC}_{50}$ values.

$\mathrm{CME}$ and $\mathrm{AE}$ were tested for their inhibitory effect on mycelial growth of $V$. inaequalis and $B$. cinerea following the poisoned food technique (Singh et al. 2008). Aliquots of the extracts were dissolved separately in $1 \mathrm{ml}$ of ultrapure water and pipetted into Petri dishes containing $19 \mathrm{ml}$ of molten PDA $\left(<40^{\circ} \mathrm{C}\right)$ under sterile conditions. The final concentrations of the fruit pericarp extracts in the agar were $1,5,10,50,100,1,000,5,000,10,000,20,000$, and $30,000 \mathrm{ppm}$ for both pathogens. Control plates were inoculated with $1.0 \mathrm{ml}$ of water following the same procedure. Mycelial plugs, $8 \mathrm{~mm}$ in diameter, from the actively growing area of $\mathrm{V} 1$ or B05.10 were placed close to the center of a PDA plate. Three replicates were set up for each concentration and incubated at $20^{\circ} \mathrm{C}$. The diameter of the fungal colonies (in millimeters) was recorded after 4 days postinoculation (dpi) for B05.10 and after 21 dpi for V1. The inhibition of mycelial growth expressed as percent of the control was calculated using the formula growth inhibition $(\%)=[(\mathrm{DC}-\mathrm{DT}) /(\mathrm{DC} \times 100)]$, where $\mathrm{DC}=$ average diameter of extract-free control and $\mathrm{DT}=$ average diameter of fungal colony with extract treatment.

The concentration that reduced the fungal colony diameter to $50 \%$ of the diameter of the untreated control $\left(\mathrm{IC}_{50}\right)$ was determined by plotting the $x-y$ values and fitting the data with a sigmoidal doseresponse model (variable slope), as described above. $R^{2}$ for $\mathrm{IC}_{50}$ values were calculated. The experiments were repeated three times and data presented are the average of three experiments. Data were analyzed using unpaired two-sided $t$ tests to determine significant differences $(P \leq 0.05)$ between $\mathrm{IC}_{50}$ values.

Greenhouse assays with fruit pericarp extract of $S$. mukorossi against $\boldsymbol{V}$. inaequalis. Seed of Malus domestica 'Golden Delicious' were stored at $5^{\circ} \mathrm{C}$. For stratification, seed were primed in ice-water for 7 days and subsequently placed in moist sand and incubated in a refrigerator (approximately $4^{\circ} \mathrm{C}$ ) for 4 to 6 weeks. Germinating seed were sown in small pots $(9 \mathrm{~cm}$ in diameter) containing standard potting soil (Floragard, Oldenburg, Germany) mixed with sand (4:1, vol/vol) and grown in a greenhouse under natural light conditions. The temperature was $20 \pm 2{ }^{\circ} \mathrm{C}$ and the relative humidity (RH) was around $80 \%$. The plants were fertilized as required to ensure continuous and vigorous growth. For plant infection assays, 4- to 6-week-old plants with three young, not yet fully expanded leaves were used. The upper fully expanded leaf of each plant was labeled by removing the tip of the leaf. Preventive treatments were applied with a hand sprayer at $24 \mathrm{~h}$ before inoculation with conidia. Plants were sprayed with a 1 or $0.1 \%$ solution $(\mathrm{vol} / \mathrm{vol})$ of CME or with ultrapure water (control) until run-off. After drying, the seedlings were packed in polyethylene bags. After $24 \mathrm{~h}$, seedlings were inoculated with a conidial suspension of $V$. inaequalis $\left(10^{6} / \mathrm{ml}\right)$ until run-off. The bags were closed immediately afterward to induce high RH. For curative treatments, plastic bags from seedlings were reopened after $24 \mathrm{~h}$. The plants were sprayed with a $1 \%$ CME solution and plastic bags were closed immediately afterward. All plastic bags were removed $48 \mathrm{~h}$ after inoculation. Disease development was monitored with thermoimaging (Testo 875-1, Lenzkirch, Germany) according to Oerke et al. (2011). Color reflectance images of the seedlings were taken with a digital camera every 2 to 3 days. Disease severity was assessed by visually rating each single plant at $28 \mathrm{dpi}$ using the categories $1=$ symptomless, $2=$ chlorotic spots, $3=$ sporulating infection, and $4=$ necrotic infection. Plants showing different categories of symptoms were rated with the highest determined category. Means and standard errors $(\%)$ were calculated. Sporulation on symptomatic plants was quantified at 28 dpi. For each treatment, the leaves of all 10 plants 
were sampled and pooled in ultrapure water. The amount of water was adjusted individually for each sample. The suspension was shaken for $10 \mathrm{~min}$. The number of conidia in the washing fluid was counted with a Kolkwitz planktoncytometer ( $0.5 \mathrm{ml}$; Hydro-Bios, Germany) and the spore production per plant for each treatment was calculated. Experiments were repeated three times. All three experiments were conducted using a randomized complete block design with 10 plants for each treatment per plot.

For statistical analyses, data of all plants displaying infection symptoms (chlorotic spots, sporulating infection, and necrotic infection) were combined and compared with symptomless plants. Data on disease severity and spore production were analyzed using AndersonDarling tests. Gaussian distributed data were further analyzed for homogeneity of variances using Levene's test. Data were combined and analyzed using an unpaired two-sided $t$ test for determining significant differences among treatments at $P \leq 0.05$. Statistical analyses were performed using Microsoft Excel 2007.

Field trials with fruit pericarp extract of $S$. mukorossi against B. cinerea. Vineyard site and experimental design. Field trials were carried out in the years 2011 to 2014 in the experimental vineyards of the Institut Viti-Vinicole in Remich, Luxembourg (latitude $49^{\circ} 32^{\prime}$ $40^{\prime \prime} \mathrm{N}$, longitude $6^{\circ} 21^{\prime} 14^{\prime \prime} \mathrm{E}$ ) on the white Vitis vinifera 'Pinot gris'. This cultivar shows a high susceptibility toward bunch rot due to its mostly compact cluster structure (Molitor et al. 2012). The experimental vineyard was planted in 2000 and the vines, grafted onto SO4 rootstocks, were trained to a vertical shoot positioning system, as previously described in detail (Molitor et al. 2015a). The space per plant was $2.4 \mathrm{~m}^{2}$ ( $2 \mathrm{~m}$ between rows, $1.2 \mathrm{~m}$ between vines). Regular background fungicide applications (10- to 12-day intervals) against Plasmopara viticola (Berk. \& M. A. Curtis) Berl. \& De Toni and Erysiphe necator Schwein. were carried out in all seasons. The active ingredients of the fungicides used are listed in Molitor et al. (2015b). No fungicides with known specific activity against $B$. cinerea (botryticides) were applied. All four experiments were conducted using a randomized complete block design with four replicates of eight vines per plot. In all treatments, leaves were manually removed from the cluster zone on the side of the rows exposed southeastward between the end of flowering (BBCH 69) and fruit-set (BBCH 71) (Lorenz et al. 1995).

Treatments were defined as follows: 1 : untreated control; 2 : aqueous fruit pericarp extract (AE) of $S$. mukorossi (seven applications in biweekly intervals between $\mathrm{BBCH} 68$ and 12 weeks thereafter); 3: AE of S. mukorossi (two applications at plant growth stage $\mathrm{BBCH}$ 77 and $\mathrm{BBCH} 81$ ); and 4: botryticide (two applications at plant growth stages BBCH 77 and $\mathrm{BBCH} 81$ ). Treatments 1, 2, and 4 were realized in all 4 years $(2011,2012,2013$, and 2014), whereas this was the case for treatment 3 only in the years 2012, 2013, and 2014. In all treatments, clusters were treated from both sides until run-off using a backpack sprayer (Solo Akku 416, Solo Kleinmotoren GmbH, Sindelfingen, Germany) equipped with injector nozzles (Albuz AVI 80-015; Agrotop Spray Technology, Obertraubling, Germany). Tap water was applied at 800 liters/ha. In treatments 2 and 3, ground fruit pericarp of $S$. mukorossi (Waschnusspulver; Fair Natur) (Molitor et al. 2010) was transferred into nylon sacs and filled sacs were incubated into a bucket of tap water for extraction. Fruit pericarp of $S$. mukorossi powder was used at $10 \mathrm{~g} /$ liter of water (concentration: $1 \%$; powder dose at $8 \mathrm{~kg} / \mathrm{ha}$ ). After $1 \mathrm{~h}$ of extraction, filled sacs were removed and the remaining suspension was used for spraying. Botryticide applications in treatment 4 consisted of one treatment with Teldor (active ingredient: fenhexamid at $500 \mathrm{~g} / \mathrm{kg}$; treatment concentration: $0.1 \%$; dose: $0.8 \mathrm{~kg} / \mathrm{ha}$ ) at BBCH 77 and one treatment with Switch (active ingredients: cyprodinil at $375 \mathrm{~g} / \mathrm{kg}$ and fludioxonil at $250 \mathrm{~g} / \mathrm{kg}$; treatment concentration: $0.06 \%$; dose: $0.48 \mathrm{~kg} / \mathrm{ha}$ ) at $\mathrm{BBCH}$ 81. Application dates are given in Table 1.

Assessment of B. cinerea disease progress. The progress of the $B$. cinerea disease severity was followed during the maturation period at weekly to biweekly intervals by visual inspection of 100 randomly selected clusters per plot (50 on each side of the row). Two (in 2013) to five (in 2014) assessments were conducted per year. Disease severity was rated according to EPPO guideline PP1/17 (http://pp1. eppo.int/list.php). Grape clusters were visually classified into seven groups: 0,1 to 5,6 to 10,11 to 25,26 to 50,51 to 75 , and 76 to $100 \%$ disease severity. Average disease severities per replicate and, based on this, per treatment were calculated. Efficacy levels of the different treatments at the final assessment were calculated as $100 \%$ minus the disease severity in the respective treatment in relation to the disease severity of the untreated control. To describe the temporal progress of the disease severity, average values were plotted versus the assessment date (expressed as day of the year [DOY]). Disease progress curves were fitted to these data using the sigmoidal equation 1 according to Molitor et al. (2016):

$$
y=\frac{100}{1+e^{-\left(\left(x-x_{0}\right) / b\right)}}
$$

where $y$ is the disease severity, $x$ corresponds to the assessment date (DOY), $x_{0}$ is the inflection point of the curve (disease severity of $50 \%$ reached) and $b$ the slope factor of the curve. Solving equation 1 for $x$ allowed the estimation of the time point at which a specific disease severity level was reached. In the present examinations, the DOY when a disease severity level of $5 \%$ was reached $\left(x_{5 \%}\right)$ values were selected as proposed by Beresford et al. (2006) and Evers et al. (2010) to compare the effect of the different treatments on the temporal position of the epidemic. The delay of the time point reaching 5\% disease severity in comparison with the untreated control was calculated by subtracting the $x_{5 \%}$ values of the untreated control from the $x_{5} \%$ values of the treatments 2 to 4 .

Statistical analysis. Recorded disease severities consisting of average values per plot (four replicate plots per treatment) were analyzed for the effect of the treatment at the final assessment date by one-way analyses of variance using the software package SPSS (version 19; IBM, Chicago). In case null-hypotheses were rejected $(P \leq 0.05)$, pairwise multiple comparisons according to Duncan (Duncan 1955) were performed for treatment effects. Checking for significant differences regarding the time point reaching $5 \%$ disease severity,

Table 1. Treatments and application dates in the field trials against Botrytis cinerea on grapevine in the different years

\begin{tabular}{|c|c|c|c|c|}
\hline Treatment $^{\mathrm{z}}$ & 2011 & 2012 & 2013 & 2014 \\
\hline 1 Untreated control & $\ldots$ & $\ldots$ & $\ldots$ & $\ldots$ \\
\hline \multirow[t]{7}{*}{$2 \mathrm{AE}$ (7 applications) } & 6 June & 22 June & 9 July & 16 June \\
\hline & 21 June & 6 July & 23 July & 1 July \\
\hline & 4 July & 20 July & 6 August & 15 July \\
\hline & 18 July & 3 August & 20 August & 29 July \\
\hline & 1 August & 17 August & 2 September & 12 August \\
\hline & 17 August & 31 August & 16 September & 26 August \\
\hline & 30 August & 14 September & 30 September & 9 September \\
\hline \multirow{2}{*}{$3 \mathrm{AE}$ (2 applications) } & $\ldots$ & 20 July & 23 July & 15 July \\
\hline & $\ldots$ & 17 August & 20 August & 12 August \\
\hline \multirow[t]{2}{*}{4 Botryticide (2 applications) } & 28 June & 20 July & 23 July & 15 July \\
\hline & 10 August & 17 August & 20 August & 12 August \\
\hline
\end{tabular}

\footnotetext{
${ }^{\mathrm{z}} \mathrm{AE}=$ aqueous extract of Sapindus mukorossi.
} 
$x_{5} \%$ values (temporally relative to $x_{5} \%$ values of treatment 1 [control] in the respective year] were compared pairwise $(P \leq 0.05)$ following an independent samples Kruskal-Wallis test (SPSS 19).

Hydrophobic interaction chromatography. Preliminary purification of the fruit pericarp extracts was achieved by using a selfpacked Phenyl Sepharose High-Performance column $(15 \times 150 \mathrm{~mm}$, particle size $=34 \mu \mathrm{m}$; GE Healthcare Europe GmbH, Freiburg, Germany). The column eluent was monitored with a UV detector $(280 \mathrm{~nm}$, 2238 Uvicord SII; LKB, Bromma, Sweden). The hydrophobic interaction chromatography (HIC) medium was equilibrated with two volumes of a buffer solution ( $20 \mathrm{mM}$ Tris and $3 \mathrm{M} \mathrm{NaCl})$. Fruit pericarp

Table 2. In vitro efficacy of different concentrations of the aqueous (AE) and chloroform-methanol (CME) extract of Sapindus mukorossi on conidial germination and radial growth inhibition of Venturia inaequalis after 28 days and of Botrytis cinerea after 4 days of incubation at $20^{\circ} \mathrm{C}^{\mathrm{z}}$

\begin{tabular}{|c|c|c|c|c|}
\hline \multirow[b]{2}{*}{ Extract (ppm) } & \multicolumn{2}{|c|}{ Growth inhibition (\%) } & \multicolumn{2}{|c|}{ Conidial germination $(\%)$} \\
\hline & V. inaequalis & B. cinerea & V. inaequalis & B. cinerea \\
\hline \multicolumn{5}{|l|}{$\overline{\mathrm{AE}}$} \\
\hline 30,000 & $100 \mathrm{a}$ & $54 \mathrm{a}$ & $0 \mathrm{a}$ & $\ldots$ \\
\hline 20,000 & $100 \mathrm{a}$ & $49 \mathrm{a}$ & $0 \mathrm{a}$ & $\ldots$ \\
\hline 10,000 & $100 \mathrm{a}$ & $41 \mathrm{a}$ & $0 \mathrm{a}$ & $\ldots$ \\
\hline 5,000 & $100 \mathrm{a}$ & $36 \mathrm{a}$ & $0 \mathrm{a}$ & $\ldots$ \\
\hline 1,000 & $99 \mathrm{a}$ & $30 \mathrm{~b}$ & $0 \mathrm{a}$ & $\ldots$ \\
\hline 500 & $95 \mathrm{a}$ & $22 \mathrm{~b}$ & $0 \mathrm{a}$ & $\ldots$ \\
\hline 100 & $37 \mathrm{~b}$ & $1 \mathrm{c}$ & $98 \mathrm{~b}$ & $\ldots$ \\
\hline 50 & $25 \mathrm{~b}$ & $0 \mathrm{c}$ & $96 \mathrm{~b}$ & $\ldots$ \\
\hline 10 & $0 \mathrm{c}$ & $0 \mathrm{c}$ & $97 \mathrm{~b}$ & $\ldots$ \\
\hline 5 & $0 \mathrm{c}$ & $0 \mathrm{c}$ & $99 \mathrm{~b}$ & $\ldots$ \\
\hline 1 & $0 \mathrm{c}$ & $0 \mathrm{c}$ & $96 \mathrm{~b}$ & $\begin{array}{l}\cdots \\
\ldots\end{array}$ \\
\hline \multicolumn{5}{|l|}{ CME } \\
\hline 30,000 & $100 \mathrm{a}$ & $74 \mathrm{a}$ & $0 \mathrm{a}$ & $\ldots$ \\
\hline 20,000 & $100 \mathrm{a}$ & $67 \mathrm{~b}$ & $0 \mathrm{a}$ & $\ldots$ \\
\hline 10,000 & $100 \mathrm{a}$ & $26 \mathrm{c}$ & $0 \mathrm{a}$ & $\ldots$ \\
\hline 5,000 & $100 \mathrm{a}$ & $20 \mathrm{c}$ & $0 \mathrm{a}$ & $\ldots$ \\
\hline 1,000 & $83 \mathrm{~b}$ & $10 \mathrm{~d}$ & $0 \mathrm{a}$ & $\ldots$ \\
\hline 500 & $70 \mathrm{~b}$ & $5 \mathrm{~d}$ & $0 \mathrm{a}$ & $\ldots$ \\
\hline 100 & $18 \mathrm{c}$ & $4 \mathrm{~d}$ & $93 \mathrm{~b}$ & $\ldots$ \\
\hline 50 & $5 \mathrm{c}$ & $3 \mathrm{~d}$ & $98 \mathrm{~b}$ & $\ldots$ \\
\hline 10 & $5 \mathrm{c}$ & $0 \mathrm{e}$ & $94 \mathrm{~b}$ & $\ldots$ \\
\hline 5 & $5 \mathrm{c}$ & $0 \mathrm{e}$ & $98 \mathrm{~b}$ & $\ldots$ \\
\hline 1 & $4 \mathrm{c}$ & $0 \mathrm{e}$ & $98 \mathrm{~b}$ & $\ldots$ \\
\hline \multicolumn{5}{|l|}{$\mathrm{AE}$} \\
\hline 300,000 & $\ldots$ & $\ldots$ & $\ldots$ & $0 \mathrm{a}$ \\
\hline 250,000 & $\ldots$ & $\ldots$ & $\ldots$ & $0 \mathrm{a}$ \\
\hline 200,000 & $\ldots$ & $\ldots$ & $\ldots$ & $3 \mathrm{a}$ \\
\hline 150,000 & $\ldots$ & $\ldots$ & $\ldots$ & $89 \mathrm{~b}$ \\
\hline 125,000 & $\ldots$ & $\ldots$ & $\ldots$ & $96 \mathrm{~b}$ \\
\hline 100,000 & $\ldots$ & $\ldots$ & $\ldots$ & $100 \mathrm{~b}$ \\
\hline 75,000 & $\cdots$ & $\cdots$ & $\cdots$ & $100 \mathrm{~b}$ \\
\hline 50,000 & $\ldots$ & $\ldots$ & $\cdots$ & $100 \mathrm{~b}$ \\
\hline 10,000 & $\ldots$ & $\cdots$ & $\begin{array}{l}\cdots \\
\ldots\end{array}$ & $100 \mathrm{~b}$ \\
\hline 1,000 & $\begin{array}{l}\cdots \\
\cdots\end{array}$ & $\begin{array}{l}\cdots \\
\cdots\end{array}$ & $\begin{array}{l}\cdots \\
\cdots\end{array}$ & $100 \mathrm{~b}$ \\
\hline 100 & $\ldots$ & $\ldots$ & $\ldots$ & $100 \mathrm{~b}$ \\
\hline \multicolumn{5}{|l|}{ CME } \\
\hline 300,000 & $\ldots$ & $\ldots$ & $\ldots$ & $0 \mathrm{a}$ \\
\hline 250,000 & $\ldots$ & $\ldots$ & $\ldots$ & $0 \mathrm{a}$ \\
\hline 200,000 & $\begin{array}{l}\cdots \\
\cdots\end{array}$ & $\cdots$ & $\cdots$ & $0 \mathrm{a}$ \\
\hline 150,000 & $\ldots$ & $\ldots$ & $\ldots$ & $7 \mathrm{a}$ \\
\hline 125,000 & $\ldots$ & $\ldots$ & $\ldots$ & $58 \mathrm{~b}$ \\
\hline 100,000 & $\ldots$ & $\ldots$ & $\ldots$ & $75 \mathrm{~b}$ \\
\hline 75,000 & $\cdots$ & $\ldots$ & $\cdots$ & $93 \mathrm{~b}$ \\
\hline 50,000 & $\cdots$ & $\cdots$ & $\cdots$ & $98 \mathrm{~b}$ \\
\hline 10,000 & $\ldots$ & $\ldots$ & $\ldots$ & $98 \mathrm{~b}$ \\
\hline 1,000 & $\ldots$ & $\ldots$ & $\ldots$ & $99 \mathrm{~b}$ \\
\hline 100 & $\ldots$ & $\ldots$ & $\ldots$ & $99 \mathrm{~b}$ \\
\hline
\end{tabular}

${ }^{\mathrm{z}}$ All values are means of three replicates per treatment of three experiments $(n=9)$. Means followed by the same letter in each column are not significantly different at $P \leq 0.05$ by two-sided $t$ test. Percent growth inhibition was calculated compared with the growth of control (100\%). extracts were dissolved in the same buffer $(100 \mathrm{mg} / \mathrm{ml})$, centrifuged for $10 \mathrm{~min}\left(16,060 \times \mathrm{g}, 20^{\circ} \mathrm{C}\right)$, and applied to the column. After washing the column with three column volumes of binding buffer, fractions were eluted with $20 \mathrm{mM}$ Tris, $\mathrm{pH} 10$, followed by a second elution step with $50 \% \mathrm{EtOH}$. The collected fractions of $2 \mathrm{ml}$ were analyzed in a self-developed agar diffusion assay supplemented with sheep erythrocytes to identify the hemolytic/membranolytic saponin fractions. The cup-plate assay was performed with $95 \mathrm{ml}$ of a phosphate buffered saline, $\mathrm{pH} 7.0$, and $1 \mathrm{~g}$ of agarose (Carl Roth $\mathrm{GmbH}$, Karlsruhe, Germany) heated to boil under constant stirring. After cooling to $42^{\circ} \mathrm{C}, 5 \mathrm{ml}$ of fresh heparinized blood collected from sheep (Acila, Mörfelden-Walldorf, Germany) was added and mixed gently. The final suspension had a concentration of erythrocytes of $0.8 \times 10^{6} / \mu 1$. The solution was poured into squared petri dishes $(120 \times 120 \mathrm{~mm}$; Greiner bio-one). A siliconized cup former was dipped in the agaroseblood medium, creating cups of about $80 \mu \mathrm{l}$ in size. The cups were filled with $80 \mu \mathrm{l}$ of the collected HIC fractions. The appearance of hydrolysis zones around the cups indicated the presence of hemolytic saponins.

The hemolytic HIC fractions were further analyzed on an HPLC system that consisted of a Beckman pump (112, solvent delivery
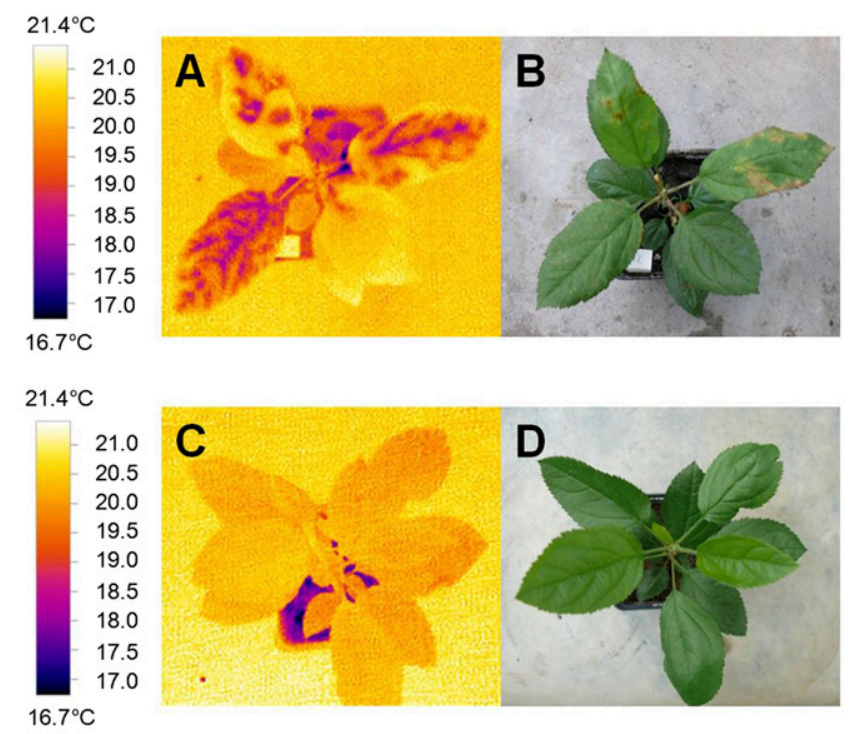

$21.8^{\circ} \mathrm{C}$
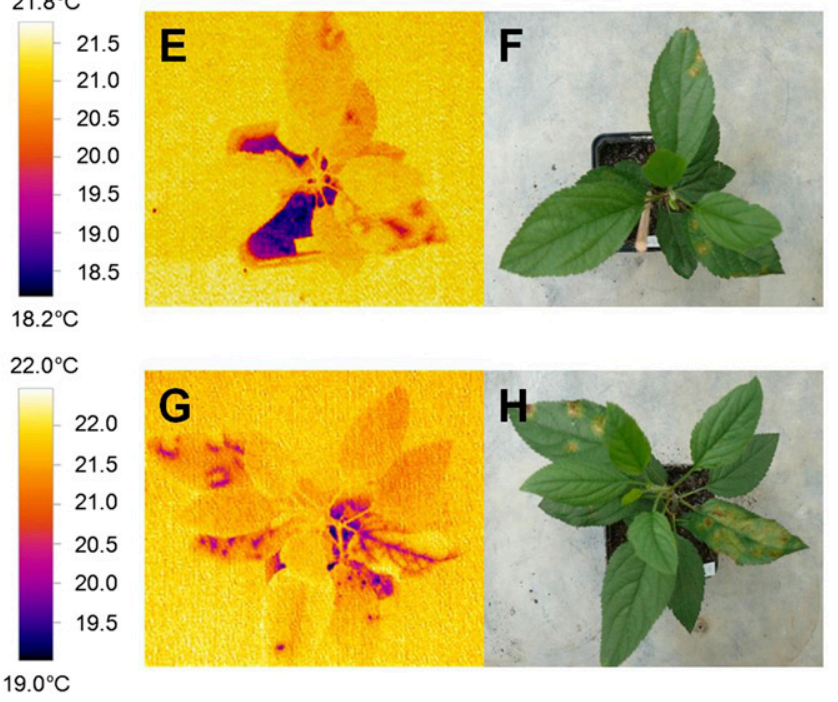

Fig. 1. Effect of treatments with the solid fraction of a chloroform-methanol extract (CME) of Sapindus mukorossi resolved in water on the development of scab colonies caused by Venturia inaequalis (V1) 28 days after infection. Scab became detectable at 6 days postinoculation (dpi) at the thermal level; areas of low leaf temperature indicated infection and proceeded visible symptoms after 10 to 12 dpi. Left, thermo-images and right, reflectance images. A and $\mathbf{B}$, Control; C and D, 1\% CME; E and F, 0.1\% CME; and $\mathbf{G}$ and $\mathbf{H}, 1 \%$ CME curative. 
module), a Rheodyne 7125 valve furnished with a $100-\mu$ l loop, a UV detector (Shimadzu, SPD 2A), a high-temperature column oven (Knauer), a Gastorr 702 degaser, and a Beckman 420 system controller. Separation of saponins was carried out using a C18 Gemini 5u 110A column $(250 \times 4.6 \mathrm{~mm}, 5-\mu \mathrm{m}$ particle size; Phenomenex, Torrance, CA) at $1.0 \mathrm{ml} \mathrm{min}^{-1}$ flow rate and protected by a Security Guard Cartridge $(4 \times 3.0 \mathrm{~mm}$, Gemini C18; Phenomenex). The HPLC mobile phase consisted of $\mathrm{H}_{2} \mathrm{O}$ with $0.1 \%$ trifluoroacetic acid (solvent $\mathrm{A}$ ) and $\mathrm{ACN}$ (solvent B). The mobile phase was degassed in an ultrasonic bath and filtered under vacuum through a membrane $(0.2 \mu \mathrm{m}$, Whatman; GE Healthcare Europe $\mathrm{GmbH}$ ) prior to use. A gradient program was used according to the following profile: 0 to $25 \mathrm{~min}, 20$ to $80 \%$ B; 25 to $30 \mathrm{~min}, 80 \% \mathrm{~B}$. Fruit pericarp extracts $(50 \mathrm{mg} / \mathrm{ml})$ were dissolved in water and filtered through a $0.45-\mu \mathrm{m}$ membrane filter (Whatman, GE Healthcare Europe $\mathrm{GmbH}$ ). A 100- $\mu$ l volume sample was injected each time via the Rheodyne injector. The retention time for each compound was measured at $203 \mathrm{~nm}$ and a sensitivity of 2.56 absorbance units full scale at a constant temperature of $35^{\circ} \mathrm{C}$. All analyses were done in triplicate for each sample. Data acquisition and processing was conducted using Apex Clarity 3.0 software (Data Apex Ltd., Prague, Czech Republic).

Evaluation of the antifungal activity of extract fractions collected by preparative HPLC was carried out by the agar well diffusion method.

Table 3. Effect of protective ( $24 \mathrm{~h})$ and curative $(24 \mathrm{~h})$ treatment of chloroformmethanol-extract (CME) from Sapindus mukorossi on disease development of $V$. inaequalis on scab-inoculated $\left(10^{5}\right.$ conidia/ml) cultivar Golden Delicious seedlings in the greenhouse ${ }^{\mathrm{z}}$

\begin{tabular}{lcccc}
\hline & \multicolumn{3}{c}{ Disease assessment category (percentage of plants) } \\
\cline { 2 - 5 } Treatment & Symptomless & $\begin{array}{c}\text { Chlorotic } \\
\text { spots }\end{array}$ & $\begin{array}{c}\text { Sporulating } \\
\text { infection }\end{array}$ & $\begin{array}{c}\text { Necrotic } \\
\text { infection }\end{array}$ \\
\hline Control & $0 \pm 0$ & $5 \pm 4$ & $50 \pm 40$ & $45 \pm 40$ \\
CME preventive 1\% & $50 \pm 0$ & $50 \pm 0$ & $0 \pm 0$ & $0 \pm 0$ \\
CME preventive & $15 \pm 4$ & $30 \pm 10$ & $20 \pm 20$ & $35 \pm 35$ \\
$\quad$ C.1\% & & & & \\
CME curative 1\% & $5 \pm 4$ & $30 \pm 20$ & $20 \pm 15$ & $45 \pm 40$ \\
\hline
\end{tabular}

${ }^{\mathrm{z}}$ Disease incidence on each plant was evaluated 28 days postinoculation using the categories $1=$ symptomless, $2=$ chlorotic spots, $3=$ sporulating infection, and $4=$ necrotic infection. Plants showing different kinds of symptoms were rated with the highest determined category. Means \pm standard error $(\%)$ obtained from analysis of 10 plants per treatment and three replications $(n=30)$.

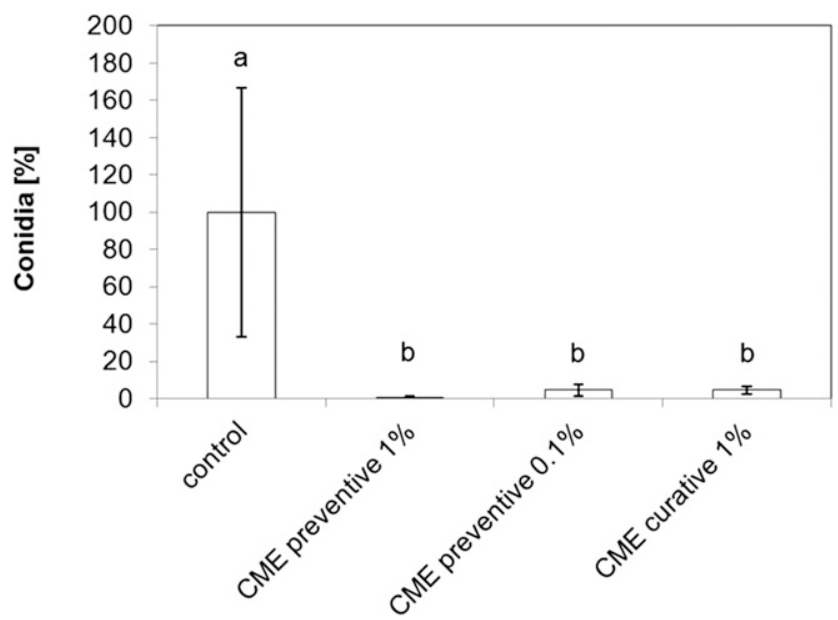

Fig. 2. Effect of protective ( $24 \mathrm{~h}$ ) and curative ( $24 \mathrm{~h})$ treatment of chloroform-methanol extract (CME) of Sapindus mukorossi on the production of conidia on scab-inoculated $\left(10^{5}\right.$ conidia/ml) cultivar Golden Delicious seedlings in the greenhouse. Conidial washings were performed 28 days postinoculation. Means represent conidia of 10 plants per treatment of three experiments $(n=30)$. The number of conidia per plant in the control was $3.9 \times 10^{4} \pm 2.6 \times 10^{4}$ (standard error [SE]). Bars with the same letters are not significantly different according to a two-sided unpaired $t$ test $(P \geq 0.05)$. Vertical bars show SE of the mean.
Cups of $8 \mathrm{~mm}$ were punched into PDA plates with a sterile cork borer. The lower portion of each well was sealed with a drop of molten PDA medium and left to settle. Cups in the PDA plates were filled with $100 \mu \mathrm{l}$ of a fractionated peak. A mycelial plug of $\mathrm{V} 1$ or B05.10 was placed at a distance of $2 \mathrm{~cm}$. The addition of $100 \mu \mathrm{l}$ of water alone into the cup served as control. Three replicates were set up for each fraction and plates were incubated at $20^{\circ} \mathrm{C}$. The diameter of fungal growth (in millimeters) was recorded after $4 \mathrm{dpi}$ for B05.10 and after 21 dpi for V1. The inhibition of mycelial growth expressed as percent of the control was calculated using the formula growth inhibition $(\%)=[(\mathrm{DC}-\mathrm{DT}) /$ $(\mathrm{DC} \times 100)$ ], where $\mathrm{DC}=$ diameter of extract-free control and DT $=$ diameter of fungal colony with extract treatment (Pandey et al. 1982).

The experiments were repeated three times and data presented are the average of three experiments. Data were analyzed using an unpaired two-sided $t$ test. Means were considered to be significantly different at $P<0.05$. Statistical analyses were performed using Microsoft Excel 2007

UPLC-TripleTOF analysis. HPLC fractions from $S$. mukorossi that had fungicidal effects in the bioassay where further analyzed by UPLC. The HPLC-fractionated peaks (retention time: 16.0 to $18.8 \mathrm{~min}$ ) were lyophilized, resuspended in $1 \mathrm{ml}$ of EtOH: $\mathrm{H}_{2} \mathrm{O}$ $(1: 1, \mathrm{vol} / \mathrm{vol})$, and filtered through a syringe filter $(0.2 \mu \mathrm{m}$, PTFE Millex-LG; Merck KGaA, Darmstadt, Germany). Extracts were analyzed with a Waters Acquity UPLC system (Milford, MA) hyphenated to a high-resolution TOF mass spectrometer (TripleTOF 5600+; AB Sciex, Concord, Ontario, Canada). The separation of the 5- $\mu$ l aliquot was performed on a reverse-phase Acquity UPLC BEH C18 column $(2.1 \times 100 \mathrm{~mm}, 1.7-\mu \mathrm{m}$ particle size; Waters $)$. The solvents were $\mathrm{A}=\mathrm{H}_{2} \mathrm{O}$ with $2.5 \mathrm{mM}$ (vol/wt) $\mathrm{NH}_{4} \mathrm{OAc}$ and $\mathrm{B}=\mathrm{ACN}$, all of liquid chromatography mass spectrometry (MS) grade. The gradient was as follows: $0 \mathrm{~min}, 1 \% \mathrm{~B} ; 4 \mathrm{~min}, 1 \% \mathrm{~B} ; 16 \mathrm{~min}, 5 \% \mathrm{~B} ; 35 \mathrm{~min}$, $40 \% \mathrm{~B} ; 45 \mathrm{~min}, 100 \% \mathrm{~B} ; 50 \mathrm{~min}, 100 \% \mathrm{~B} ; 53 \mathrm{~min}, 1 \% \mathrm{~B}$; and $60 \mathrm{~min}, 1 \% \mathrm{~B}$. The flow rate was $0.5 \mathrm{ml} \mathrm{min}^{-1}$ and the column temperature was $50^{\circ} \mathrm{C}$. Analytes were negatively ionized with an electrospray ionization source using the following parameter values: source temperature of $650^{\circ} \mathrm{C}$, ion spray voltage of $-4.5 \mathrm{kV}$, curtain gas (nitrogen) of $30 \mathrm{psi}$, nebulizer gas (air) of $55 \mathrm{psi}$, and turbine gas (air) of 50 psi. Precursor charge state selection was set at 1 . For information dependent acquisition in high sensitivity mode, survey scans were acquired in $175 \mathrm{~ms}$ and the 10 most abundant product ion scans were

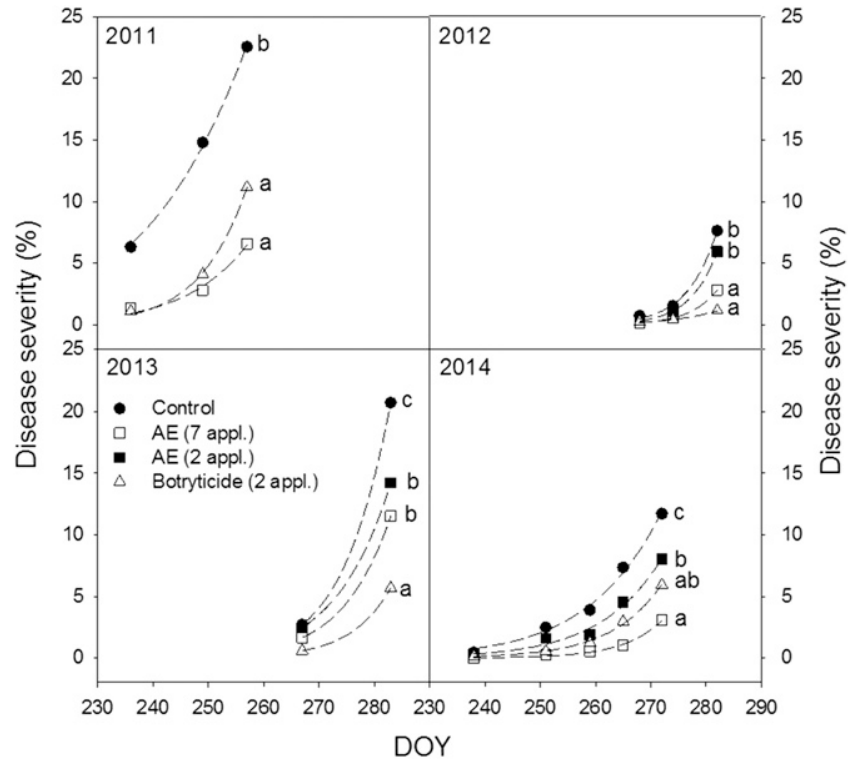

Fig. 3. Progress of the disease severity of Botrytis cinerea in the years 2011 to 2014 as functions of the assessment date (day of the year [DOY]). Plot symbols represent the observed disease severities and the dashed lines the calculated progress according to the sigmoidal equation type $y=100 /\left\{1+e^{-[(x-x 0) / b]}\right\}$. Treatments in the same year marked with the same letter did not differ significantly at the final assessment date (according to Duncan's multiple comparison procedure; $a=5 \%$ ). $A E=$ aqueous extract of Sapindus mukorrossi. 
collected if exceeding a threshold of 100 counts/s. The total cycle time was fixed at $2.225 \mathrm{~s}$. A sweeping collision energy setting of $15 \mathrm{eV}$ was applied to all precursor ions for collision-induced dissociation. The declustering potential was set at $-60 \mathrm{eV}$. Dynamic exclusion was set for $8 \mathrm{~s}$ after two occurrences, and then the precursor was refreshed of the exclusion list. For MS1, full high resolution (HR)-MS spectra between 100 and 1,300 mass-to-charge ratio $(\mathrm{m} / \mathrm{z})$ were recorded. MS2 scans were recorded between 25 and 1,300 m/z.

Structure elucidation. The software PeakView (v 1.2 0.3; AB Sciex) combined with the Metlin (https://metlin.scripps.edu/index. php) and PubChem (https://pubchem.ncbi.nlm.nih.gov) databases as well as literature data were used for structure elucidation.

\section{Results}

Inhibitory effects of the fruit pericarp extract of $S$. mukorossi on the test fungi under in vitro conditions. Both $S$. mukorossi fruit pericarp extracts inhibited the germination of conidia of $V$. inaequalis completely at concentrations of $\geq 500 \mathrm{ppm}$ (Table 2). No effect on germination was observed at concentrations $\leq 100 \mathrm{ppm}$. According to sigmoidal regression analysis, $\mathrm{CME}$ and $\mathrm{AE}$ from $S$. mukorossi showed $\mathrm{IC}_{50}$ values of 123 and $140 \mathrm{ppm}$, respectively. $\mathrm{IC}_{50}$ values of $\mathrm{CME}$ and $\mathrm{AE}$ were not significantly different $(P \geq 0.05)$. Germination of conidia of $B$. cinerea was inhibited completely at concentrations $\geq 250,000 \mathrm{ppm}$. $\mathrm{IC}_{50}$ values were $110,168 \mathrm{ppm}$ for CME and $167,770 \mathrm{ppm}$ for AE. $R^{2}$ of the sigmoidal regression used to estimate $\mathrm{IC}_{50}$ values for $V$. inaequalis and $B$. cinerea ranged from 0.96 to 0.99 , with the estimated $\mathrm{IC}_{50}$ values of both extracts being not significantly different $(P \geq 0.05)$.

Mycelial growth data of both fungal species are presented in Table 2 . The results showed that mycelial growth was considerably reduced with increasing concentrations of $\mathrm{CME}$ and $\mathrm{AE}$. A concentration of $\geq 5,000 \mathrm{ppm}$ resulted in complete growth inhibition of $V$. inaequalis. According to sigmoidal regression analysis, $\mathrm{CME}$ showed an $\mathrm{IC}_{50}$ of $284 \mathrm{ppm}$ and $\mathrm{AE}$ an $\mathrm{IC}_{50}$ of $125 \mathrm{ppm}$. Growth of $B$. cinerea was reduced by $74 \%$ with $\mathrm{CME}$ and by $54 \%$ with $\mathrm{AE}$ at a concentration of $30,000 \mathrm{ppm}$. The $\mathrm{IC}_{50}$ was estimated to be $18,551 \mathrm{ppm}$ for $\mathrm{CME}$ and $22,920 \mathrm{ppm}$ for AE. $R^{2}$ for both pathogens ranged from 0.91 to 0.98 . At the same concentration, the efficacy (mycelial growth) of both extracts was not significantly different $(P \geq 0.05)$.

Greenhouse assays with fruit pericarp extract of $S$. mukorossi against $V$. inaequalis. Provided that infection was successful, scab symptoms on seedling leaves appeared 10 to 12 days after inoculation. By using thermal infrared imaging, the symptoms became visible after 6 days. Infected leaf areas had a temperature of 17.5 to $19^{\circ} \mathrm{C}$ (Fig. 1), whereas the temperature of healthy apple leaves ranged from 20 to $22^{\circ} \mathrm{C}$. Spraying apple leaves with $1 \% \mathrm{CME} 24 \mathrm{~h}$ before inoculation with conidia reduced the scab symptoms significantly $(P \leq 0.05)$ compared with control treatment (Table 3$)$. All of the control plants showed infection symptoms, whereby $45 \%$ of the plants showed necrotic infections, $50 \%$ showed sporulating infections, and $5 \%$ displayed chlorotic spots. In contrast, $50 \%$ of the $1 \%$ preventive-treated seedlings displayed only chlorotic spots and $50 \%$ of the plants were symptomless. The leaf temperature on leaves displaying chlorotic spots was 20 to $22^{\circ} \mathrm{C}$ and corresponds with the leaf temperature measured on healthy leaves. The $0.1 \%$ preventive and the $1 \%$ curative treatments with $\mathrm{CME}$ were less effective $(P \geq 0.05)$ compared with the $1 \%$ preventive treatment. The plants showed sporulating $(20 \%)$ and also necrotic (35 to $45 \%$ ) infections. Likewise, all treatments reduced conidial production of $V$. inaequalis significantly $(P \leq 0.05)$ on apple leaves according to a two-sided unpaired $t$ test (Fig. 2). Although the number of conidia per plant in the control was $3.9 \times 10^{4} \pm$ $2.6 \times 10^{4}$ (standard error), the scores for 1 and $0.1 \%$ preventive CME and $1 \%$ curative CME treatment were $0.04 \times 10^{4} \pm 0.02 \times 10^{4}, 0.18 \times$ $10^{4} \pm 0.12 \times 10^{4}$, and $0.14 \times 10^{4} \pm 0.08 \times 10^{4}$, respectively. The consistency of the data was confirmed in three experiments.

Field trials with fruit pericarp extract of $S$. mukorossi against B. cinerea. Final (immediately prior to harvest) disease severities in the untreated control ranged from 7.6 to $22.6 \%$ (Fig. 3). In all 4 years, the highest final disease severities were observed in the untreated control. Average efficacy levels (average values of the efficacy levels of all four experiments) at the final bunch rot assessment were $63.0 \%$ (treatment 2: AE [seven applications]), $28.3 \%$ (treatment 3: AE [two applications]) and $64.3 \%$ (treatment 4: botryticide [two applications]). At the final assessment, the disease severity in treatments 2 and 4 in all years was significantly lower than in the untreated control. For treatment 3, this was the case in 2013 and 2014. In 3 of 4 years, no statistical difference between the disease severities in the treatments 2 and 4 was observed at the final assessment (Fig. 3).

Sigmoidal equations of the type $y=\frac{100}{1+e^{-\left(\left(x-x_{0}\right) / \mathrm{b}\right)}}$ were well adapted to the recorded disease progress. $R^{2}$ ranged from 0.98 to 1.00 , with $P$ values between $<0.0001$ and 0.0927 (Fig. 3, Table 4).

All treatments delayed the point of time when a disease severity level of $5 \%$ was reached, regardless of year. The average delays were 11.6 days for treatment 2 (AE [seven applications]), 3.0 days for

Table 4. Parameters describing the disease progress curves according to the sigmoidal equation type $y=100 /\left\{1+\mathrm{e}^{-\left[\left(\mathrm{x}-\mathrm{x}_{0}\right) / \mathrm{b}\right]}\right\}$ as well as the temporal delay of the date reaching $5 \%$ disease severity compared with the untreated control in the four experimental years ${ }^{\mathrm{z}}$

\begin{tabular}{|c|c|c|c|c|c|c|}
\hline Year, treatment & $R^{2}$ & $P$ value & $b$ & $x_{0}$ & $x_{5 \%}(\mathrm{DOY})$ & Delay $x_{5 \%}$ (days) \\
\hline \multicolumn{7}{|l|}{2011} \\
\hline 1 Untreated control & 0.9990 & 0.0206 & 14.6 & 274.9 & 231.9 & $\ldots$ \\
\hline $2 \mathrm{AE}$ (7 applications) & 0.9789 & 0.0927 & 10.7 & 285.2 & 253.8 & 21.9 \\
\hline $3 \mathrm{AE}$ (2 applications) & $\ldots$ & $\ldots$ & $\ldots$ & $\ldots$ & $\ldots$ & $\ldots$ \\
\hline 4 Botryticide (2 applications) & 0.9981 & 0.0278 & 7.7 & 272.9 & 250.3 & 18.5 \\
\hline \multicolumn{7}{|l|}{2012} \\
\hline 1 Untreated control & 0.9978 & 0.0297 & 5.0 & 294.5 & 279.7 & $\ldots$ \\
\hline 2 AE (7 applications) & 1.0000 & 0.0012 & 4.9 & 299.2 & 284.9 & 5.1 \\
\hline $3 \mathrm{AE}$ (2 applications) & 0.9992 & 0.0174 & 4.7 & 294.9 & 281.2 & 1.4 \\
\hline 4 Botryticide (2 applications) & 0.9942 & 0.0486 & 8.1 & 318.0 & 294.2 & 14.5 \\
\hline \multicolumn{7}{|l|}{2013} \\
\hline 1 Untreated control & 1.0000 & $\ldots$ & 7.1 & 292.6 & 271.6 & $\ldots$ \\
\hline $2 \mathrm{AE}$ (7 applications) & 1.0000 & $\ldots$ & 7.8 & 298.9 & 275.9 & 4.4 \\
\hline $3 \mathrm{AE}$ (2 applications) & 1.0000 & $\ldots$ & 8.6 & 298.4 & 273.2 & 1.6 \\
\hline 4 Botryticide (2 applications) & 1.0000 & $\ldots$ & 6.9 & 302.3 & 282.0 & 10.5 \\
\hline \multicolumn{7}{|l|}{2014} \\
\hline 1 Untreated control & 0.9934 & 0.0002 & 12.0 & 295.9 & 260.5 & $\ldots$ \\
\hline $2 \mathrm{AE}$ (7 applications) & 0.9952 & 0.0001 & 6.9 & 295.9 & 275.5 & 15.0 \\
\hline $3 \mathrm{AE}$ (2 applications) & 0.9842 & 0.0008 & 10.4 & 297.2 & 266.7 & 6.2 \\
\hline 4 Botryticide ( 2 applications) & 0.9969 & $>0.0001$ & 8.8 & 296.2 & 270.4 & 9.8 \\
\hline
\end{tabular}

${ }^{\mathrm{z}} R^{2}=$ coefficient of determination, $P$ value $=$ significance, $b=$ slope factor of the curve, $x_{0}=$ inflection point of the curve, $x_{5} \%=$ day of the year $(\mathrm{DOY})$ reaching a disease severity of $5 \%$, and $\mathrm{AE}=$ aqueous extract of Sapindus mukorossi. 
treatment 3 (AE [two applications]), and 11.9 days for treatment 4 (botryticide [two applications]) (Table 4). Kruskal-Wallis tests for independent samples showed that the temporal delay of the epidemic compared with the untreated control was significant in case of the treatments 2 and 4 . The delay caused by treatment 3 was not significant compared with the other three treatments. No significant differences in the time point reaching $5 \%$ disease severity were observed between the treatments 2 and 4 .

S. mukorossi fruit pericarp extract and its constituents. Purification of saponin extracts by using HIC was conducted by HPLC analysis. The representative chromatograms of the plant extracts resulting from chloroform-methanol extraction and the HIC purified extract are presented in Figure 4. A comparison between both chromatograms revealed that nonhemolytic peaks, with a retention time between 0 and $10 \mathrm{~min}$, were removed almost completely by HIC purification. However, all of the hemolytic peaks detected in CME extract between 16 and $20 \mathrm{~min}$ were also present in the HIC purified extract.

One fraction detected by HPLC (16 to $20 \mathrm{~min})(5 \mu \mathrm{g}$ per $100 \mu \mathrm{l})$ showed significant inhibitory activity $(P=0.02)$ against the mycelial growth of $V$. inaequalis $(46 \pm 6 \%)$ and reduced the mycelial growth of $B$. cinerea by $43 \pm 2 \%(P=0.056)$. In the HIC chromatogram, this peak had a larger peak area (39\%) compared with the crude extract. Early and late eluting components ( 0.0 to 16.0 and 20 to $30 \mathrm{~min}$, respectively) had no effect on the mycelial growth of both fungal pathogens.

UPLC-Triple-TOF analysis of the fungicidal fraction (16 to $20 \mathrm{~min}$ ) revealed the presence of three saponins as well as some minor unknown components (Fig. 5). The detected saponins were identified on the basis of their mass spectra in negative ion modes, combined with the relevant literature data (Table 5). The fungicidal S. mukorossi peak showed a $[\mathrm{M}-\mathrm{H}]^{-}$molecular anion at 881.4924, corresponding to the formula $\mathrm{C}_{46} \mathrm{H}_{74} \mathrm{O}_{16}$. The MS fragmentation led to the generation of three main daughter ions, resulting from the loss of one pentose (likely xylopyranose, $-132 \mathrm{Da}$ ), one deoxyhexose (likely rhamnopyranose, $-146 \mathrm{Da}$ ), and another pentose (likely arabinose, $-132 \mathrm{Da}$ ). The smallest daughter ion, at $\mathrm{m} / \mathrm{z} 471.3484$, represented the aglycone ion, hederagenin. Therefore, the compound could be putatively identified as sapindoside B, a triterpenoid saponin (Chirva et al. 1970; Saxena et al. 2004). In addition to the major compound, two minor peaks at 34.58 and $36.16 \mathrm{~min}$ were also characterized as potential saponins. The first one showed a $[\mathrm{M}-\mathrm{H}]]^{-}$molecular anion at 765.4442 , corresponding to the formula $\mathrm{C}_{41} \mathrm{H}_{60} \mathrm{O}_{13}$ (hederageninpentosyl-hexoside), whereas the second one, with a daughter ion at $\mathrm{m} / \mathrm{z} 455.3543$, could be assigned as oleanolic acid-hexosyldeoxyhexosyl-hexoside.

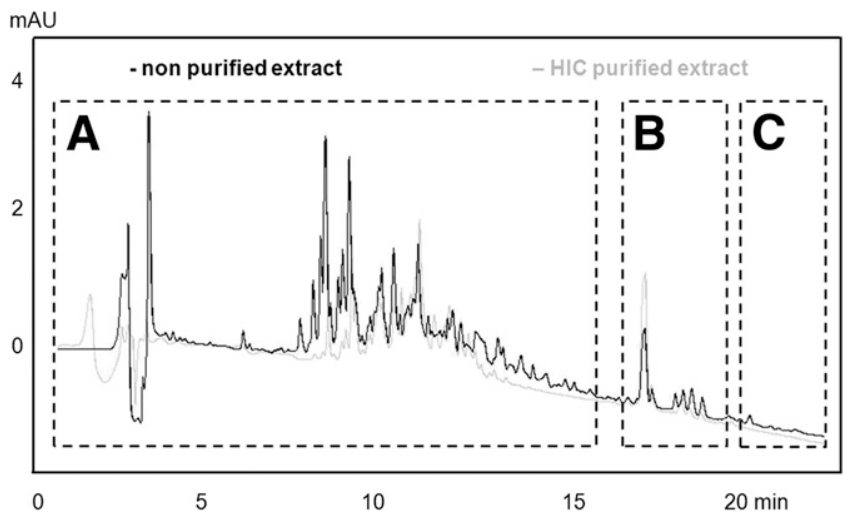

Fig. 4. High-performance liquid chromatography (HPLC) of the fruit pericarps of Sapindus mukorossi. The black line represents the chromatogram of the saponin extract resulting from chloroform-methanol extraction $(\mathrm{CME})$, whereas the gray line shows the hydrophobic interaction chromatography (HIC) purified extract. The HPLC fractions of both extracts were investigated for hemolytic and membranolytic activity with a cup-plate assay amended with sheep erythrocytes. A, Nonhemolytic fraction between 0 and $16 \mathrm{~min}$; B, hemolytic fraction between 16 and $20 \mathrm{~min}$; and C, nonhemolytic fraction, 20 to $30 \mathrm{~min}$. $\mathrm{mAU}=$ milliabsorbance unit.

\section{Discussion}

Saponins are considered to show high antifungal activity (Osbourn 1996). In this study, we tested for the first time saponin-rich fruit pericarp extracts of $S$. mukorossi against the plant-pathogenic fungi $V$. inaequalis and $B$. cinerea. The results show a dose-dependent inhibition of conidial germination and mycelial growth of both fungal pathogens.

The efficacies of the two different saponin extracts used in this study were not significantly different $(P \geq 0.05)$ (Table 2). However, spore germination and mycelial growth of $B$. cinerea was not as strongly affected by the extracts as the spore germination and mycelial growth of $V$. inaequalis. The cause for the different antifungal activities of the fruit pericarp extracts on $V$. inaequalis and $B$. cinerea might be related to differences in the membrane sterol content of these species. The ability of saponins to cause membrane perturbation depends on membrane composition, especially in regard to concentration level and structure of incorporated membrane sterols (Augustin et al. 2011; Roddick and Drysdale 1984; Walker et al. 2008). As demonstrated by Gögelein and Hüby (1984), the steroidal saponin digitonin induced channel-like fluctuations in cholesterolcontaining and cholesterol-free lipid membranes. However, with cholesterol-rich lipids, the amount of saponins needed to induce effects in planar bilayers and monolayers was much lower than was the case with cholesterol-free membranes. Steel and Drysdale (1988) could confirm these observations for fungal species. In their

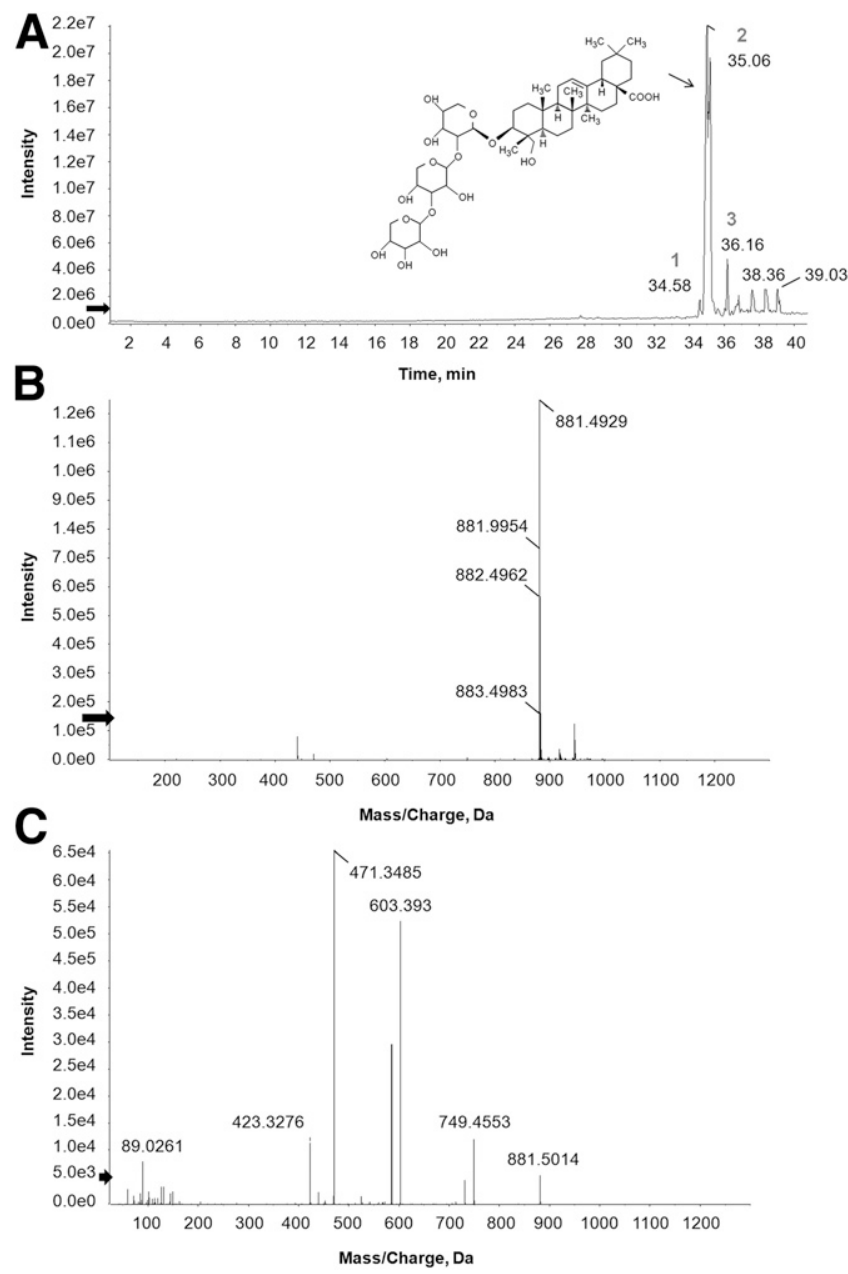

Fig. 5. A, Total ion chromatogram of the fungicidal fraction of fruit pericarp extract from Sapindus mukorossi obtained by ultrahigh-performance liquid chromatography triple time-of-flight in negative electrospray ionization mode, peak 2 showing major saponin sapindoside B (molecular mass 881.4924), peak 1 putatively identified as hederageninpentosyl-hexoside, and peak 3 as oleanolic acid-hexosyl-deoxyhexosyl-hexoside; B, mass spectrometry (MS) spectrum of sapindoside B; and C, MS2 spectrum of sapindoside $B$. 
experiments, lipsosomes prepared with a free $3 \beta$-hydroxy sterol (ergosterol, cholesterol, or sitosterol) were found to be sensitive to disruption by the saponine $\alpha$-tomatine. In contrast, liposomes lacking a free $3 \beta$-hydroxy sterol were found to be resistant to $\alpha$-tomatine. The fungal pathogens of tomato B. cinerea and Fusarium solani were found to be more resistant to the tomato saponine $\alpha$-tomatine than the nonpathogenic fungi $F$. graminearum and Penicillium expansum.

Another cause for the differential antifungal activity of $S$. mukorossi fruit pericarp extract on both fungal pathogens might be that some fungi can produce detoxifying glycosidases that remove sugar molecules from the $\mathrm{C}-3$ carbon position to give products that are less toxic to fungal growth (Bouarab et al. 2002; Osbourn 1996). The importance of saponin-detoxifying enzymes in determining fungal pathogenicity to plants has been demonstrated for $B$. cinerea, which detoxified the tomato saponin $\alpha$-tomatin, resulting in the aglycon, tomatidine (Osbourn 1996; Quidde et al. 1998). B. cinerea also degraded avenacin, avenacosides, and digitonin and possesses more than one saponin-specific enzyme (Quidde et al. 1998). Possibly, $B$. cinerea might also detoxify saponins from $S$. mukorossi, resulting in the lower antifungal activity compared with $V$. inaequalis. Furthermore, at higher concentrations of the extract, inhibition leveled off. Recent research on saponin-containing bitter melon (Momordica charantia) extracts revealed that the water solubility of aqueous or ethanol freeze-dried saponin powder is only between 69 to $79 \%$ (Tan et al. 2014). This is most likely due to the extraction of some nonpolar compounds that reduce solubility. The solubility of sapindoside $\mathrm{B}$, the major component of both extracts, in water is predicted between $3.81 \mathrm{e}^{-07}$ to $3.06 \mathrm{e}^{-04} \mathrm{~mol} /$ liter (https://comptox.epa.gov/dashboard/ dsstoxdb/results?search=DTXSID40276505). Possibly, in our experiments, the maximum solubility of $\mathrm{AE}$ and $\mathrm{CME}$ in water has been reached and led to the level-off inhibition at higher extract concentrations.

As reported in the present study, the treatment of apple seedling leaves with CME revealed significant control of scab under greenhouse conditions. The $S$. mukorossi extract reduced apple scab symptoms and sporulation on leaves. According to Oerke et al. (2011), scab symptoms could be visualized in greenhouse experiments by thermal infrared imaging 6 dpi due to a lower leaf temperature at the infection sites. Hyphal growth of $V$. inaequalis in the subcuticular area effected the transpiration of the plant, resulting in a localized decrease in leaf temperature before visual symptoms (10 to $12 \mathrm{dpi}$ ) appeared.

Spraying apple leaves protectively ( $24 \mathrm{~h}$ before inoculation) with $1 \%$ CME significantly reduced scab symptoms on seedling leaves, and no difference in leaf temperature could be detected. However, $50 \%$ of the $1 \%$ CME-treated plants displayed chlorotic spots. Possibly, these chlorotic spots resulted from lesions where scab infection was stopped by protectively $1 \%$ CME treatment. Obviously the development of subcuticular hyphae or sporulation was restricted to a small area. Small lesions have a very limited effect on plant transpiration and, therefore, the effect on plant tissue temperature is restricted (Oerke et al. 2011). In addition, chlorotic spots on apple leaves caused by scab infections are generally associated with reduced secondary stromata (Chevalier et al. 1991). When conidiophores differentiated, they rapidly aborted and no or few conidia were produced (Chevalier et al. 1991; Zhdanov and Sedov 2002). The low number of conidia detected in the washing fluid of protectively $1 \%$ CME-treated plants in this study supports these earlier observations. The inhibition of conidial germination and mycelia growth by the CME extract in vitro indicates that the high protective activity of the CME extract observed in greenhouse trials may be attributed to the inhibition of conidial germination or fungal subcuticular growth.

A markedly lower level of protection was reached with the protective $0.1 \% \mathrm{CME}$ and the $1 \%$ curative ( $24 \mathrm{~h}$ after inoculation) treatment. The results are in line with studies from Koch et al. (2013). The authors found a lower curative activity for saponin extracts from Primula sp. and Hedera helix compared with the protective treatment against Phyllostica ampelicida. These observations indicate that saponin extracts act mainly by a direct fungitoxic effect on conidial germination, germ tube development, or appressoria formation (Bengtsson et al. 2009). However, the CME extract in seedling assays of the current study (Figs. 1 and 2) may also have some cuticularpenetration effects, which was supported by the curative control of scab ( $24 \mathrm{~h}$ postinoculation). The effect of saponins on postpenetration events of $V$. inaequalis was also observed for yucca extract in studies from Bengtsson et al. (2009). Further studies should be initiated to evaluate the practical relevance of protective and curative activity of CME extract in the field.

Promising results to control gray mold with saponin extracts under in vitro conditions are reported in the literature (Quidde et al. 1998; Ribera et al. 2008). In the field trials performed here, $1 \% \mathrm{AE}$ (seven applications) significantly reduced disease severity of $B$. cinerea on the white Vitis vinifera 'Pinot gris' at the final assessment date compared with the untreated control. Note that the concentrations given here reflect the initial situation at the time of application and that the concentrations may increase due to the evaporation of the carrier substance water after application. In 3 of 4 years, the efficacy of seven applications of $1 \%$ AE did not differ significantly at the final assessment date from the efficacy of the commercial botryticides (two applications). The time point reaching a disease severity of $5 \%$ was delayed, on average, by 11.6 days. Especially under cool climate conditions, the timing of the grape harvest is determined by health status (Molitor et al. 2012). Here, a delay of the bunch rot epidemic induced by the application of $\mathrm{AE}$ allowed for a later harvest date, resulting in more advanced grape maturity and, in consequence, higher potential wine quality.

The antifungal activity of $S$. mukorossi extracts against Venturia inaequalis and B. cinerea was linked to the hemolytic/membranolytic potential. Therefore, hemolytic fractioning was confirmed to represent an appropriate and easy method to detect fungicidal saponin fractions from HIC with the developed agar-diffusion assay. All antifungal compounds were successfully bounded and concentrated at the Phenyl Sepharose column by using the mechanism of HIC. There was no loss of bioactive molecules, as proven further in HPLC analysis.

Table 5. List of compounds putatively identified in the hemolytic and fungicidal extract of Sapindus mukorossi ${ }^{z}$

\begin{tabular}{|c|c|c|c|c|c|c|c|c|}
\hline \multirow[b]{2}{*}{ Putative identity } & \multirow[b]{2}{*}{$t_{\mathbf{r}(\min )}$} & \multirow[b]{2}{*}{ Error (ppm) } & \multirow[b]{2}{*}[\mathrm{M}-\mathrm{H}]{$^{-}$} & \multirow[b]{2}{*}{ MS/MS [M-H] ${ }^{-}$} & \multirow[b]{2}{*}{ Molecular formula } & \multirow[b]{2}{*}{$\Lambda \max (\mathbf{n m})$} & \multicolumn{2}{|c|}{$\begin{array}{c}\text { Relative } \\
\text { abundance }\end{array}$} \\
\hline & & & & & & & CME & $\mathbf{A E}$ \\
\hline \multirow[t]{2}{*}{ 1. Hederagenin-pentosyl-hexoside } & 34.58 & 2.9 & 765.4442 & 603.3935 & $\mathrm{C}_{41} \mathrm{H}_{66} \mathrm{O}_{13}$ & 1 & $3.0 \times 10^{5}$ & $9.2 \times 10^{4}$ \\
\hline & & & & 471.3478 & & $\ldots$ & & \\
\hline \multirow{3}{*}{$\begin{array}{l}\text { 2. Hederagenin-pentosyl-rhamnosyl- } \\
\text { pentoside (Sapindoside B) }\end{array}$} & 35.06 & 3.5 & 881.4924 & 749.4548 & $\mathrm{C}_{46} \mathrm{H}_{74} \mathrm{O}_{16}$ & 214 & $1.7 \times 10^{7}$ & $2.2 \times 10^{7}$ \\
\hline & $\ldots$ & $\ldots$ & $\ldots$ & 603.3926 & $\ldots$ & $\ldots$ & $\ldots$ & $\ldots$ \\
\hline & $\ldots$ & $\ldots$ & $\ldots$ & 471.3484 & $\ldots$ & $\ldots$ & $\ldots$ & $\ldots$ \\
\hline \multirow{3}{*}{$\begin{array}{l}\text { 3. Oleanolic acid-hexosyl-deoxyhexosyl- } \\
\text { hexoside }\end{array}$} & 36.16 & 5.3 & 925.5204 & 763.4724 & $\mathrm{C}_{48} \mathrm{H}_{78} \mathrm{O}_{17}$ & l & $7 \times 10^{3}$ & nd \\
\hline & $\ldots$ & $\ldots$ & $\ldots$ & 617.4104 & $\cdots$ & $\ldots$ & $\ldots$ & $\ldots$ \\
\hline & $\ldots$ & $\ldots$ & $\ldots$ & 455.3543 & $\ldots$ & $\ldots$ & $\ldots$ & $\ldots$ \\
\hline
\end{tabular}

${ }^{\mathrm{z}}$ Data were obtained by ultrahigh-performance liquid chromatography triple time-of-flight in negative electrospray ionization mode, with tandem mass spectrometry (MS/MS) experiments; $t_{\mathrm{r}}=$ retention time, $[\mathrm{M}-\mathrm{H}]^{-}=$molecular anion, $\Lambda$ max $=$ absorbance maximale, $\mathrm{CME}=$ chloroform-methanol extract of $S$. mukorossi, $\mathrm{AE}=$ aqueous extract of $S$. mukorossi and nd = not detected. 
One fraction (16 to $20 \mathrm{~min}$ ) detected by HPLC in both $S$. mukorossi extracts showed potent antifungal activity against the mycelial growth of $V$. inaequalis and $B$. cinerea. Furthermore, this fraction produced a stable foam upon shaking with water, indicating the presence of surfactants. UPLC-Triple-TOF analysis revealed that the fraction consisted of three compounds having sapindoside B (Chirva et al. 1970; Saxena et al. 2004) as the major component, accounting for $>98 \%$ of the total identified compounds in both extracts (Table 5). To the best of our knowledge, this is the first report demonstrating the antifungal activity of $S$. mukurossi saponins, and of sapindoside B in particular, against the plant pathogens $V$. inaequalis and $B$. cinerea.

Sapindoside B has previously been reported in $S$. mukorossi extracts (Saxena et al. 2004) and the mass spectral data obtained in the current study are in a good agreement with these reports. The strong foaming capacity and hemolytic activity of the HPLC fraction containing sapindoside B was also observed by Wu et al. (2014). The authors reported antimicrobial activity of sapindoside B against dermatophytes.

Two saponins occurred in lower abundance in the fungicidal fraction. The first minor peak at 34.58 min was putatively identified as hederagenin-pentosyl-hexoside, whereas the aglycone of the second peak at 6.16 min can be assigned as oleanolic acid (Table 5). The presence of this aglycone in extracts from $S$. mukorossi has been described previously (Wu et al. 2014) and is also reported in the species S. saponaria (Murgu and Rodrigues 2006).

The results from the present study demonstrate that $S$. mukorossi extract has an interesting potential as an alternative control agent for use against scab and gray mold in organic production. When using raw extracts from $S$. mukorossi, as was done in the greenhouse and field trial of the present study, mixtures with active ingredients from other mode-of-action groups should be considered and investigated to prevent a quick adaptation of the pathogens to the fungicidal constituents of the extract. The identification of sapindoside B as an effective compound opens the possibility to synthesize structurally similar molecules with increased bioefficacy.

The application of $S$. mukorossi extract has also been demonstrated to reduce the disease development of other fungal pathogens in vineyards. Molitor et al. (2010) reported that an aqueous fruit pericarp extract from $S$. mukorossi reduced disease severities of Plasmopara viticola and Guignardia bidwellii on grapevine leaves in the greenhouse. Regarding G. bidwellii, this effect was confirmed in clusters in the field. The observed efficacy (75 to 90\%) was comparable with standard products (Thiovit Jet, active ingredient sulfur) when the extract was applied immediately prior to inoculation.

The present results indicate that it is worthwhile to analyze the fungicidal fraction with nuclear magnetic resonance to provide further information for absolute structural characterization of the three putatively identified saponins and to test these saponins individually against the fungi to elucidate their efficacy. In addition, it would be of great interest to test UV stability, solubility, and toxicity of these saponins toward a set of further plant-pathogenic organisms that are also evaluated in the screening of synthetic fungicides. Finally, the aim would be to synthesize or extract the effective constituent in a cost-effective manner and make this fungicidal constituent fit for widespread use in integrated or organic horticulture and viticulture.

\section{Acknowledgments}

We thank T. Mayer, A. Engelhard, V. Greulich, J. P. Petras, and K. Ehlert (Julius Kühn-Institute) as well as M. Behr, M. Pallez, B. Untereiner, N. Baron, R. Rausch, M. Schultz, and L. Vesque (Luxembourg Institute of Science and Technology [LIST]) for technical support; M. Schultz, R. Mannes, and S. Fischer (Institut Viti-Vinicole, Remich) for providing the experimental vineyards; A. S. Walker (Institut National de la Recherche Agronomique, Thiverval-Grignon) for providing the $B$. cinerea isolate B05.10; and D. Evers (LIST) for fruitful discussion.

\section{Literature Cited}

Agnello, A. 2017. 2017 Cornell Pest Management Guidelines for Commercial Tree Fruit Production. Cornell Cooperative Extension, Ithaca, NY.

Amselem, J., Cuomo, C. A., van Kan, J. A. L., Viaud, M., Benito, E. P., Couloux, A., Coutinho, P. M., de Vries, R P., Dyer, P. S., Fillinger, S., Fournier, E., Gout,
L., Hahn, M., Kohn, L., Lapalu, N., Plummer, K. M., Pradier, J.-M., Quévillon, E., Sharon, A., Simon, A., ten Have, A., Tudzynski, B., Tudzynski, P., Wincker, P., Andrew, M., Anthouard, V., Beever, R. E., Beffa, R., Benoit, I., Bouzid, O., Brault, B., Chen, Z., Chouquer, M., Collémare, J., Cotton, P., Danchin, E. G. Da Silva, C., Gautier, A., Giraud, C., Giraud, T., Gonzalez, C., Grossetete, S., Güldener, U., Henrissat, B., Howlett, B. J., Kodira, C., Kretschmer, M., Lappartient, A., Leroch, M., Levis, C., Mauceli, E., Neuvéglise, C., Oeser, B., Pearson, M., Poulain, J., Poussereau, N., Quesneville, H., Rascle, C., Schumacher, J., Ségurens, B., Sexton, A., Silva, E., Sirven, C., Soanes, D. M., Talbot, N. J., Templeton, M., Yandava, C., Yarden, O., Zeng, Q., Rollins, J. A., Lebrun, M.-G., and Dickman, M. 2011. Genomic analysis of the necrotrophic fungal pathogens Sclerotinia sclerotiorum and Botrytis cinerea. PLoS Genet. 7:e1002230.

Augustin, J. M., Kuzina, V., Andersen, S. B., and Bak, S. 2011. Molecular activities, biosynthesis and evolution of triterpenoid saponins. Phytochemistry 72:435-457.

Bengtsson, M., Wulff, E., Jorgensen, H. J. L., Pham, A., Lubeck, M., and Hockenhull, J. 2009. Comparative studies on the effects of a yucca extract and acibenzolar-S-methyl (ASM) on inhibition of Venturia inaequalis in apple leaves. Eur. J. Plant Pathol. 124:187-198.

Beresford, R. M., Evans, K. J., Wood, P. N., and Mundy, D. C. 2006. Disease assessment and epidemic monitoring methodology for bunch rot (Botrytis cinerea) in grapevines. N. Z. Plant Prot. 59:1-6.

Bouarab, K., Melton, R., Peart, J., Baulcombe, D., and Osbourn, A. 2002. A saponin-detoxifying enzyme mediates suppression of plant defences. Nature 418:889-892.

Carisse, O., and Dewdney, M. 2002. A review of non-fungicidal approaches for the control of apple scab. Phytoprotection 83:1-29.

Chapagain, B. P., Wiesman, Z., and Tsror (Lahkim), L. 2007. In vitro study of the antifungal activity of saponin-rich extracts against prevalent phytopathogenic fungi. Ind. Crops Prod. 26:109-115.

Chapman, K. S., Sundin, G. W., and Beckerman, J. L. 2011. Identification of resistance to multiple fungicides in field populations of Venturia inaequalis. Plant Dis. 95:921-926.

Chevalier, M., Lespinasse, Y., and Renaudin, S. 1991. A microscopic study of the different classes of symptoms coded by the $V f$ gene in apple for resistance to scab (Venturia inaequalis). Plant Pathol. 40:249-256.

Chirva, V. Y., Kintya, P. K., Sosnovskii, V. A., Krivenchuk, P. E., and Zykova, N. Y. 1970. Triterpene glycosides of Sapindus mukorossi. Chem. Nat. Compd. 6:213-215.

Choi, G. J., Kim, J. C., Jang, K. S., Lim, H. K., Park, I. K., Shin, S. C., and Cho, K Y. 2006. In vivo antifungal activities of 67 plant fruit extracts against six plant pathogenic fungi. J. Microbiol. Biotechnol. 16:491-495.

Duncan, D. B. 1955. Multiple range and multiple F tests. Biometrics 11:1-42.

Evers, D., Molitor, D., Rothmeier, M., Behr, M., Fischer, S., and Hoffmann, L. 2010. Efficiency of different strategies for the control of grey mold on grapes including gibberellic acid (Gibb3), leaf removal and/or botryticide treatments. J. Int. Sci. Vigne Vin 44:151-159.

Gabaston, J., Richard, T., Biais, B., Waffo-Teguo, P., Pedrot, E., Jourdes, M., Corio-Costet, M. F., and Merillion, J. M. 2017. Stilbenes from common spruce (Picea abies) bark as natural antifungal agent against downy mildew (Plasmopara viticola). Ind. Crops Prod. 103:267-273.

Gilliom, R. J. 2007. Pesticides in US streams and groundwater. Environ. Sci. Technol. 41:3408-3414.

Gögelein, H., and Hüby, A. 1984. Interaction of saponin and digitonin with black lipid membranes and lipid monolayers. Biochim. Biophys. Acta 773:32-38

Huang, H.-C., Wu, M.-D., Tsai, W.-J., Liao, S.-C., Liaw, C.-C., Hsu, L.-C., Wu, Y.-C., and Kuo, Y.-H. 2008. Triterpenoid saponins from the fruits and galls of Sapindus mukorossi. Phytochemistry 69:1609-1616.

Ibrahim, M., Khan, A. A., Tiwari, S. K., Habeeb, M. A., Khaja, M., and Habibullah, C. 2006. Antimicrobial activity of Sapindus mukorossi and Rheum emodi extracts against $H$. pylori: In vitro and in vivo studies. World J. Gastroenterol. 12:7136-7142.

JKI. 2017. Behandlungshäufigkeit (Pesticide application frequencies of selected crops in Germany). Online publication. Julius Kühn-Institute (JKI). http:// papa.julius-kuehn.de/index.php?menuid $=46$

Kassemeyer, H.-H., and Berkelmann-Löhnertz, B. 2009. Fungi of grapes. Pages 61-87 in: Biology of Microorganisms on Grapes, in Must and in Wine. H. König, G Unden, and J. Fröhlich, eds. Springer-Verlag, Berlin, Heidelberg, Germany.

Koch, E., Enders, M., Ullrich, C., Molitor, D., and Berkelmann-Lohnertz, B. 2013. Effect of Primula root and other plant extracts on infection structure formation of Phyllosticta ampelicida (asexual stage of Guignardia bidwellii) and on black rot disease of grapevine in the greenhouse. J. Plant Dis. Prot. 120:26-33.

Kollar, A. 1994. Characterization of specific induction, activity, and isozyme polymorphism of extracellular cellulases from Venturia inaequalis detected in vitro and on the host plant. Mol. Plant-Microbe Interact. 7:603-611.

Köller, W., and Wilcox, W. F. 2001. Evidence for the predisposition of fungicideresistant isolates of Venturia inaequalis to a preferential selection for resistance to other fungicides. Phytopathology 91:776-781.

Köller, W., Wilcox, W. F., and Parker, D. M. 2005. Sensitivity of Venturia inaequalis populations to anilinopyrimidine fungicides and their contribution to scab management in New York. Plant Dis. 89:357-365. 
Lorenz, D. H., Eichhorn, K. W., Bleiholder, H., Klose, R., Meier, U., and Weber, E. 1995. Phenological growth stages of the grapevine, Vitis vinifera L. ssp. vinifera. Codes and descriptions according to the extended $\mathrm{BBCH}$ scale. Aust. J. Grape Wine Res. 1:100-103.

MacHardy, W. E. 1996. Apple scab: Biology, Epidemiology, and Management. American Phytopathology Society, St. Paul, MN.

Molitor, D., Baron, N., Sauerwein, T., André, C., Kicherer, A., Döring, J., Stoll, M., Beyer, M., Hoffmann, L., and Evers, D. 2015a. Postponing first shoot topping reduces grape cluster compactness and delays bunch rot epidemic. Am. J. Enol. Vitic. 66:164-176.

Molitor, D., Baus, O., Hoffmann, L., and Beyer, M. 2016. Meteorological conditions determine the thermal-temporal position of the annual Botrytis bunch rot epidemic on Vitis vinifera L. cv. Riesling grapes. Oeno One 55: 231-244.

Molitor, D., Behr, M., Hoffmann, L., and Evers, D. 2012. Impact of grape cluster division on cluster morphology and bunch rot epidemic. Am. J. Enol. Vitic. 63: 508-514.

Molitor, D., Heibertshausen, D., Baus, O., Loskill, B., Maixner, M., and Berkelmann-Löhnertz, B. 2010. Einsatz eines Sapindus mukorossi-Extraktes zur Regulierung von pilzlichen Pathogenen an Weinreben-Eine Alternative für den ökologischen Rebschutz? J. Kultpflanzen 62:444-450.

Molitor, D., Hoffmann, L., and Beyer, M. 2015b. Flower debris removal delays grape bunch rot epidemic. Am. J. Enol. Vitic. 66:548-553.

Murgu, M., and Rodrigues, E. 2006. Dereplication of glycosides from Sapindus saponaria using liquid chromatography-mass spectrometry. J. Braz. Chem. Soc. 17:1281-1290.

Oerke, E. C., Froehling, P., and Steiner, U. 2011. Thermographic assessment of scab disease on apple leaves. Precis. Agric. 12:699-715.

Osbourn, A. 1996. Saponins and plant defence-A soap story. Trends Plant Sci. 1:4-9.

Palou, L., Ali, A., Fallik, E., and Romanazzi, G. 2016. GRAS, plant- and animalderived compounds as alternatives to conventional fungicides for the control of postharvest diseases of fresh horticultural produce. Postharvest Biol. Technol. 122:41-52.

Pandey, D. K., Tripathi, N. N., Tripathi, R. D., and Dixit, S. N. 1982. Fungitoxic and phytotoxic properties of the essential oil of Hyptis suaveolens. J. Plant Dis. Prot. 89:344-349.

Parween, T., Jan, S., Mahmooduzzafar, S., Fatma, T., and Siddiqui, Z. H. 2016. Selective effect of pesticides on plant-A review. Crit. Rev. Food Sci. Nutr. 56:160-179.

Pennel, D. 2006. Food Standards Agency Pesticide Residue Minimisation Crop Guide-Apples. Online publication. https://www.food.gov.uk/sites/default/ files/multimedia/pdfs/cropguideappledec06.pdf

Pertot, I. 2013. Innovative Crop Protection for Sustainable Agriculture (PURE) Cropping System Grape vine. Online publication. http://www.pure-ipm.eu/ taxonomy/term/31

Porsche, F. M. 2015. Erfo rschung und Entwicklung alternativer Mittelzubereitungen für die Apfelschorfbekämpfung im Falllaub. Julius Kühn-Institute, Quedlinburg, Germany.

Porsche, F. M., and Kollar, A. 2013. Saponins from Sapindus mukorossi: Extraction, purification and biological activity against apple scab. Page 42 in Nachwuchswissenschaftlerforum 171. Berichte aus dem Julius Kühn-Institut, Quedlinburg, Germany.

Quidde, T., Osbourne, A. E., and Tudzynski, P. 1998. Detoxification of $\alpha$-tomatine by Botrytis cinerea. Physiol. Mol. Plant Pathol. 52:151-165.

Rafi, H., Dawar, S., and Zaki, M. J. 2015. Seed priming with extracts of Acacia nilotica (L.) Willd. ex Delile and Sapindus mukorossi (L.) plant parts in the control of root rot fungi and growth of plants. Pak. J. Bot. 47:1129-1135.

Ribera, A., Cotoras, M., and Zuniga, G. E. 2008. Effect of extracts from in vitrogrown shoots of Quillaja saponaria Mol. on Botrytis cinerea Pers. World J. Microbiol. Biotechnol. 24:1803-1811.

Ribereau-Gayon, P. 1983. Alterations of wine quality caused by Botrytis damages. Vignevini 10:48-52.
Roddick, J. A., and Drysdale, R. B. 1984. Destabilization of liposome membranes by the steroidal glycoalkaloid $\alpha$-tomatine. Phytochemistry 23:543-547.

Romanazzi, G., Lichter, A., Gabler, F. M., and Smilanick, J. L. 2012. Recent advances on the use of natural and safe alternatives to conventional methods to control postharvest gray mold of table grapes. Postharvest Biol. Technol. 63:141-147.

Roßberg, D. 2016. Survey on application of pesticides in agriculture. J. Kultpflanzen 68:25-37.

Saha, S., Walia, S., Kumar, J., and Parmar, B. S. 2010. Structure-biological activity relationships in triterpenic saponins: The relative activity of protobassic acid and its derivatives against plant pathogenic fungi. Pest Manage. Sci. 66: 825-831.

Sanborn, M., Basil, K., Vakil, C., Kerr, K., and Ragan, K. 2012. Systematic review of pesticides human health effects. Online publication. The Ontario College of Family Physicians. http://ocfp.on.ca/docs/pesticides-paper/2012-systematicreview-of-pesticide.pdf

Sanborn, M., Kerr, K. J., Sanin, L. H., Cole, D. C., Bassil, K. L., and Vakil, C. 2007. Non-cancer health effects of pesticides: Systematic review and implications for family doctors. Can. Fam. Physician 53:1712-1720.

Saxena, D., Pal, R., Dwivedi, A. K., and Singh, S. 2004. Characterisation of sapindosides in Sapindus mukorossi saponin (reetha saponin) and quantitative determination of sapindoside B. J. Sci. Ind. Res. 63:181-186.

Sharma, A., Sati, S. C., Sati, O. P., Sati, M. D., Kothiyal, S. K., Semwal, D. K., and Mehta, A. 2013. A new triterpenoid saponin and antimicrobial activity of ethanolic extract from Sapindus mukorossi Gaertn. J. Chem. 2013: Article 218510.

Singh, P., Srivastava, B., Kumar, A., Kumar, R., Dubey, N. K., and Gupta, R. 2008. Assessment of Pelargonium graveolens oil as plant-based antimicrobial and aflatoxin suppressor in food preservation. J. Sci. Food Agric. 88: 2421-2425.

Steel, C. C., and Drysdale, R. B. 1988. Electrolyte leakage from plant and fungal tissues and disruption of liposome membranes by $\alpha$-tomatine. Phytochemistry 27:1025-1030.

Tamura, Y., Mizutani, K., Ikeda, T., Ohtani, K., Kasai, R., Yamasaki, K., and Tanaka, O. 2001. Antimicrobial activities of saponins of pericarps of Sapindus mukurossi on dermatophytes. Nat. Med. 55:11-16.

Tan, S. P., Vuong, Q. V., Stathopoulos, C. E., Parks, S. E., and Roach, P. D. 2014. Optimized aqueous extraction of saponins from bitter melon for production of a saponin-enriched bitter melon powder. J. Food Sci. 79:E1372-E1381.

Thuerig, B., Ramseyer, J., Hamburger, M., Oberhansli, T., Potterat, O., Scharer, H J., and Tamm, L. 2016. Efficacy of a Juncus effusus extract on grapevine and apple plants against Plasmopara viticola and Venturia inaequalis, and identification of the major active constituent. Pest Manage. Sci. 72:1718-1726.

United States National Research Council Board of Agriculture. 1987. Regulating Pesticides in Food-The Delaney Paradox. National Academy Press, Washington DC

United States National Research Council Board of Agriculture. 1993. Pesticides in the Diets of Infants and Children. National Academy Press, Washington DC.

USDA-NASS. 2006. Agricultural Chemical Usage 2005 Fruit Summary. United States Department of Agriculture-National Agricultural Statistics Service (USDA-NASS), Washington, DC.

Walker, B. W., Manhanke, N., and Stine, K. J. 2008. Comparison of the interaction of tomatine with mixed monolayers containing phospholipid, egg sphingomyelin, and sterol. Biochim. Biophys. Acta 1778:2244-2257.

Williamson, B., Tudzynsk, B., Tudzynski, P., and van Kan, J. A. L. 2007. Botrytis cinerea: The cause of grey mould disease. Mol. Plant Pathol. 8:561-580.

Wilson, C. L., Solar, J. M., El Ghaouth, A., and Wisniewski, M. E. 1997. Rapid evaluation of plant extracts and essential oils for antifungal activity against Botrytis cinerea. Plant Dis. 81:204-210.

Wu, H., Zhang, L., Wang, N., Guo, Y., Weng, Z., Sun, Z., Xu, D., Xie, Y., and Yao, W. 2014. Analysis of the bioactive components of Sapindus saponins. Ind. Crops Prod. 61:422-429.

Zhdanov, V. V., and Sedov, E. N. 2002. Breeding for the digenic apple resistance to scab. Russ. J. Genet. 38:1411-1416. 